NASA/TM-1998-207646

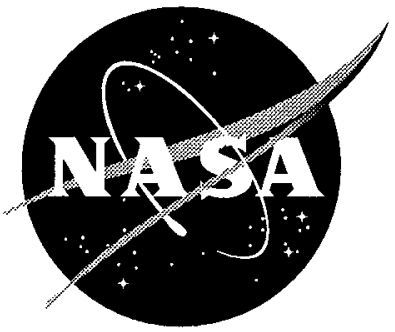

\title{
A Progressive Damage Methodology for Residual Strength Predictions of Notched Composite Panels
}

Timothy W. Coats and Charles E. Harris

Langley Research Center, Hampton, Virginia

National Aeronautics and

Space Administration

Langley Research Center

Hampton, Virginia 23681-2199 
Available from the following:

NASA Center for AeroSpace Information (CASI)

7121 Standard Drive

Hanover, MD 21076-1320

National Technical Information Service (NTIS)

5285 Port Royal Road

Springfield, VA 22161-2171

(301) 621-0390 


\title{
A PROGRESSIVE DAMAGE METHODOLOGY FOR RESIDUAL STRENGTH PREDICTIONS OF NOTCHED COMPOSITE PANELS
}

\author{
Timothy W. Coats \\ Resident Research Associate \\ National Research Council \\ and \\ Charles E. Harris \\ Chief Technologist for Structures and Materials \\ NASA Langley Research Center \\ Hampton, VA 23681
}

\begin{abstract}
The translaminate fracture behavior of carbon/epoxy structural laminates with through-penetration notches was investigated to develop a residual strength prediction methodology for composite structures. An experimental characterization of several composite materials systems revealed a fracture resistance behavior that was very similar to the R-curve behavior exhibited by ductile metals. Fractographic examinations led to the postulate that the damage growth resistance was primarily due to fractured fibers in the principal load-carrying plies being bridged by intact fibers of the adjacent plies. The load transfer associated with this bridging mechanism suggests that a progressive damage analysis methodology will be appropriate for predicting the residual strength of laminates with through-penetration notches. A progressive damage methodology developed by the authors was used to predict the initiation and growth of matrix cracks and fiber fracture. Most of the residual strength predictions for different panel widths, notch lengths, and material systems were within about $10 \%$ of the experimental failure loads.
\end{abstract}

KEY WORDS: composites, damage, matrix cracks, fiber fracture, internal state variable, residual strength. 


\title{
NOMENCLATURE
}

\author{
$\mathrm{a}_{0} \quad$ Initial Half Crack Length (Before Damage), $\mathrm{cm}$ \\ $\mathrm{E}_{11} \quad$ Lamina Longitudinal Modulus, GPa \\ E22 Lamina Transverse Modulus, GPa \\ $\mathrm{G}_{12} \quad$ Lamina In-Plane Shear Modulus, GPa \\ L Length, $\mathrm{cm}$ \\ P Applied Far-Field Load, $\mathrm{kN}$ \\ Q \\ $\mathrm{S}_{\mathrm{cr}}^{\mathrm{X}} \quad$ Lamina Critical Longitudinal Strength, $\mathrm{MPa}$ \\ $\mathrm{S}_{\mathrm{cr}}^{\mathrm{xy}} \quad$ Lamina Critical Shear Strength, MPa \\ $\mathrm{S}_{\mathrm{cr}}^{\mathrm{y}} \quad$ Lamina Critical Transverse Strength, MPa \\ w Width, cm \\ $\alpha_{\mathrm{kl}} \mathrm{L} \quad$ Internal State Variable, $\mathrm{cm} / \mathrm{cm}$ \\ $d \alpha_{\mathrm{kl}_{\mathrm{L}}} \quad$ Incremental Change in the Internal State Variable, $\mathrm{cm} / \mathrm{cm}$ \\ $\beta \quad$ Monotonic Damage Growth Parameter for Mode I Matrix Cracking \\ $\varepsilon_{\mathrm{kl}} \mathrm{L}_{\mathrm{L}} \quad$ Local Strain, $\mathrm{cm} / \mathrm{cm}$ \\ $\varepsilon_{11}^{\mathrm{cr}} \quad$ Critical Longitudinal Uniaxial Strain, $\mathrm{cm} / \mathrm{cm}$ \\ $\varepsilon_{22}^{\mathrm{cr}} \quad$ Critical Transverse Uniaxial Strain, $\mathrm{cm} / \mathrm{cm}$ \\ $\gamma \quad$ Monotonic Damage Growth Parameter for Fiber Fracture \\ $\gamma_{12}^{\mathrm{o}} \quad$ Yield Shear Strain, $\mathrm{cm} / \mathrm{cm}$ \\ $\gamma_{12}^{\mathrm{cr}} \quad$ Critical Shear Strain, $\mathrm{cm} / \mathrm{cm}$ \\ $v_{12} \quad$ Lamina Poisson's Ratio \\ o $\quad$ Applied Far-Field Stress, MPa \\ $\sigma_{\mathrm{ij}_{\mathrm{L}}} \quad$ Longitudinal Ply Stress, MPa \\ $\psi \quad$ Monotonic Damage Growth Parameter for Mode II Matrix Cracking
}




\section{INTRODUCTION}

Structural damage tolerance has been an underlying issue driving much of the research in laminated composite materials. Damage tolerance is broadly defined as the attribute of a structure that permits it to retain its required residual strength for a period of usage after the structure has sustained specific levels of fatigue, corrosion, accidental or discrete source damage. Continuous fiber-reinforced composite materials are generally fatigue and corrosion resistant and are typically designed to be tolerant of nonvisible impact damage and fail-safe from discrete source damage accidents such as an uncontained engine failure. The design of a damage tolerant structure requires a methodology capable of determining the residual strength of a major structural component after damage. Historically, metallic airframe primary structures have been designed to sustain large crack-like throughpenetrations, such as a 2-bay skin crack with a broken frame, that characterize the threat of an uncontained engine failure. Composite primary structures must also be designed for the same threats as metallic structures. Therefore, methodology must be developed to determine the residual strength of a composite structure with through-penetration damage.

Significant prior research has been conducted to characterize the damage tolerance of composite materials and structures. Fracture toughness and residual strength of various fibrous composites was studied by Poe [1]. Poe found in his investigations of brittle laminated composites that linear elastic fracture mechanics (LEFM) could be used to determine the fracture toughness of notched composite panels. These results were accurate only when damage at the notch-tips was small. Harris and Morris [2] conducted studies on translaminate fracture in thick notched composite laminates in which they determined the influence of stacking sequence and the role of delamination. They used $\mathrm{x}$-ray radiographs and fractographs of deplied specimens to observe the extent of fiber fracture, matrix splitting, and delamination in thin (8 plies) and thick (120 plies) laminates. It was found that the substantial matrix splitting and delaminations that occurred in the thin laminates occurred only in the outer surface layers for the thick laminates. The interior plies of the 
thick laminates exhibited a self-similar fracture that was uniform and relatively free of delaminations. Harris [3] also conducted an investigation into the use of crack-tip opening displacement with a Dugdale-type model to predict notched laminate strength. Similar investigations by Poe et al. [4], using the deply technique, revealed the ply-by-ply fiber fracture occurring prior to complete laminate failure. Poe et al. [5] also found that LEFM predictions were too conservative, but damage growth resistance curves (R-curves) determined from unstiffened panels resulted in reasonably accurate predictions of notched composite panels with straps and stiffeners.

The characterization of damage in notched composite laminates has also led to the development of progressive damage models to predict damage initiation, damage growth, and residual strength. Chamis [6] studied structural characteristics such as natural frequencies and buckling loads and the corresponding mode shapes during progressive fracture of angle-plied polymer matrix composites. Chamis also predicted residual strength of laminates using a finite element formulation. This study concluded that the individual nature of the structural change was dependent on laminate configuration, fiber orientation, and the boundary conditions. Talreja $[7,8]$ proposed a model that incorporated internal state variables (ISV's) for matrix cracks and delaminations and exhibited ply stacking sequence dependence. The ISV's are strain-like quantities which represent the damage as volume averaged quantities. Ladeveze [9] also developed a progressive damage methodology employing the basic concepts of continuum damage mechanics. Ladeveze and co-workers have employed internal state variables to quantify the damage state and to vary the material moduli. This approach was utilized to model fiber fracture, matrix cracking, fiber-matrix debonding, and delamination in composite laminates and woven composites loaded in tension. Chang et al. $[10,11]$ used a progressive damage analysis to predict damage growth and failure of an open-hole tension composite specimen. The failure analysis consisted of property degradation models and failure criteria for matrix cracking as well as fiber and fiber-matrix shearing failure. 
Allen and Harris developed a damage-dependent constitutive model [12-15] which utilizes kinematic-based volume averaged damage variables to represent the effects of matrix cracking and fiber fracture. This model has a matrix crack growth law for fatigue as well as monotonic tension. The kinematic effects of delaminations are modeled empirically. An experimental verification of the accuracy of the model to predict stiffness loss in toughened matrix composite systems was documented by Coats [16].

The objective of the research reported herein is to develop a progressive damage methodology capable of predicting the residual strength of continuous fiber-reinforced, laminated, polymer matrix composites with through-penetration damage. The fracture behavior of center-crack tension panels, see Figure 1, with thin crack-like slits was studied. Since fibers are the major load-carrying constituent in polymer matrix composites, predicting the residual strength of a laminate requires a criterion for fiber fracture. The effects on fiber strain due to other damage mechanisms such as matrix cracking and delaminations must also be modeled. Therefore, the research herein examines the damage mechanisms involved in translaminate fracture and identifies the toughening mechanisms responsible for damage growth resistance in brittle epoxy matrix systems. The mechanics of matrix cracking and fiber fracture are discussed as is the mathematical framework for the progressive damage model developed by the authors. The progressive damage analysis algorithms have been implemented into a general purpose finite element code [17] developed by NASA, the Computational Structural Mechanics Testbed (COMET). Damage growth is numerically simulated and the analytical residual strength predictions are compared to experimental results for a variety of notched panel configurations and materials systems.

In this paper, first the details of the various experiments conducted are presented along with a discussion of the fracture behavior exhibited by the composite panels. Next, the progressive damage methodology is presented. This includes a discussion on the nonlinear damage-dependent constitutive model, the structural analysis algorithm and failure 
mechanics, and some details of the finite element analysis. After comparing the predicted values of residual strength to the experimental values, a discussion of the computational results addresses the issues of material property sensitivities and model accuracy.

\section{EXPERIMENTAL CHARACTERIZATION}

\section{Experimental Procedure}

\section{$\underline{\text { Material and Specimen Configuration }}$}

Center-notch tension panels used in the experimental characterizations were $91 \mathrm{~cm}$ wide, $230 \mathrm{~cm}$ long, and had a notch length of $22.86 \mathrm{~cm}$. A typical center-notch tension (CNT) specimen is shown in Figure 1. After the panels were fractured in an experimental characterization, the undamaged material was used to make smaller specimens that were $10.16 \mathrm{~cm}$ and $30.5 \mathrm{~cm}$ wide. The $10.16 \mathrm{~cm}$ wide panels had notch lengths of $1.27 \mathrm{~cm}$ and $2.54 \mathrm{~cm}$. The $30.5 \mathrm{~cm}$ panels had notch lengths of $7.62 \mathrm{~cm}$. These dimensions were chosen to characterize panels with two $(2 \mathrm{a} / \mathrm{w})$ ratios and to observe panel width effects. The notches were made using an ultrasonic cutter. This process resulted in notches that were $0.5 \mathrm{~mm}$ wide and notch-tips that were not smooth radial notch-tips.

For each panel configuration, the fracture behavior of the AS4/8553-40, AS4/938, and AS4/3501-6 material systems was investigated. The laminate stacking sequence was $[\mp 45 / 0 / 90 / \mp 30 / 0]_{\mathrm{S}}$ for all panels and material systems. The AS4/3501-6 panels were manufactured using a prepreg tape while the other panels were manufactured using a towplacement technique. The $8553-40$ resin is a toughened resin and the other resins are conventional epoxies. All the test materials with their test identification names, material identifications, dimensions, and manufacturing techniques are summarized in Table 1.

The constituent materials were not available to evaluate the lamina material properties, and since a complete and consistent set of data for the lamina material properties was not available, the lamina material properties were obtained from various references in the literature and are summarized in Table 2. Lamina properties for AS4/3501-6 were taken 
from ASTM STP 1156 [18] while AS4/938 and AS4/8553-40 lamina properties were taken from Boeing test data [19]. Fiber volume fraction for each of the $91 \mathrm{~cm}$ wide panels was measured by the authors to compare with the fiber volume fractions of the materials found in the literature. The lamina material properties for AS4/8553-40 from reference 19 correspond to a material with a fiber volume fraction of about 53\%. Therefore, the rule of mixtures was applied to obtain the lamina material properties in Table 2 for AS4/8553-40 to adjust for the measured fiber volume fraction of $58 \%$ by the authors. Iosipescu shear test data [20] was used to approximate quantities for the shear failure terms.

\section{Specimen Preparation}

The $10.16 \mathrm{~cm}$ wide notched panels and $2.54 \mathrm{~cm}$ wide unnotched coupons were monotonically loaded to failure in a $222 \mathrm{kN}$ servo-hydraulic testing machine. The $30.5 \mathrm{~cm}$ and $91 \mathrm{~cm}$ wide panels were supported with anti-buckling guide plates just above and below the notch. These specimens were loaded to failure in a $445 \mathrm{kN}$ and $2220 \mathrm{kN}$ servohydraulic testing machine, respectively. Specimens were strain gaged and the strain data and applied load given by the load cell were recorded during this test. A ring gage was secured in the notch midway between the ends of the notch $(x=0, y=0$ in Figure 1$)$ to record the center-notch opening displacement.

\section{Loading and Data Collection}

As the notched panel was loaded, there were audible sounds associated with the subcritical microcrack damage (fiber fracture, delamination, and matrix cracking local to the notch tip). As damage progressed with increasing load, a zinc-iodide dye penetrant was applied periodically to the notch. In-situ x-ray radiographs were taken of the right and left notch-tip regions. The damaged material absorbed the zinc-iodide dye penetrant and is represented in the $\mathrm{x}$-ray radiograph as a blackened or shaded region in Figure 2. The panel failed catastrophically as the load was increased. This strength at failure is called the residual strength of the notched panel.

Some of the panels were not loaded to catastrophic failure. Instead, the specimen was 
unloaded after taking a series of $\mathrm{x}$-ray radiographs and removed from the test machine. Then the area surrounding the notch tip was deplied. Experimental observations of fiber fracture, matrix cracking, and delamination are discussed in the following paragraphs.

\section{Experimental Observations of Damage Growth}

The experimental techniques used in this study for observing and documenting damage growth in the notched composite laminates were: 1) x-ray radiography of the notch-tip damage and 2) fractographs of deplied specimens. The observations and documentation are discussed in the following paragraphs.

\section{$\underline{\text { X-Ray Radiography }}$}

Notch-tip damage typical of a CNT specimen was documented with x-ray radiography and is shown in Figure 2. The x-ray radiograph in this figure was taken at $89.6 \%$ of the catastrophic failure load at the right notch-tip of a $91 \mathrm{~cm}$ wide AS4/938 specimen. The farfield strain of the panel was $2050 \mu \varepsilon$ when this $\mathrm{x}$-ray radiograph was taken. A dimensioned drawing of the CNT specimen is displayed to the left of the x-ray radiograph and the actual dimensions of the x-ray radiograph are given to aid in visualizing the extent of the notch-tip damage zone. A "dark black tear" extending from the notch-tip is identified as fiber fracture. The surrounding shaded region is in the form of local delamination and the thin lines extending from the notch-tip correspond to matrix cracks in the off-axis plies. This damage state represents the damage tolerated at this load level before catastrophic failure. The pattern and extent of damage displayed in Figure 2 was similar and typical for the other material systems. Furthermore, there were no noticeable differences in the $\mathrm{x}$-ray radiographs between the panels made with the conventional epoxies and the panels made with the toughened resin, $8553-40$.

The applied load and the crack opening displacement (COD) at the center of the notch was recorded and used to produce load vs. COD plots as shown in Figure 3. A schematic of the center-notch tension panel is presented with an illustration of the loading configuration and the location for COD measurements. The data displayed in this figure is 
for an AS4/938 panel with a width of $30.5 \mathrm{~cm}$ and a notch length of $7.6 \mathrm{~cm}$.

Discontinuities, or jumps, exist at various places along the load vs. COD plot where the damage was audible during loading. The specimen was unloaded at the occurrence of each of these discontinuities to take an X-ray radiograph. Each of the radiographs are labeled A, $\mathrm{B}, \mathrm{C}$, and D in Figure 3. These $\mathrm{x}$-ray radiographs and the corresponding loads are provided in the plot to illustrate the amount of notch-tip damage corresponding to the applied load at each discontinuity. The damage and the notch size shown in the x-ray radiographs are actual size.

It was observed that for each consecutive loading, additional damage did not occur until the loads at which previous damage had occurred were exceeded. This stable damage growth process continued during the loading of the panel and made it possible to obtain $\mathrm{x}$ ray radiographs of the extensive notch-tip damage. The damage modes illustrated in Figures 2 and 3 is typical of all three of the material systems investigated.

\section{Fractography of Ply Level Damage}

Five specimens were chosen to be loaded up to $84 \%-94 \%$ of the average ultimate failure load. An x-ray radiograph was taken and then the notch-tip damage region was isolated and pyrolized in an oven for about four hours at $450^{\circ} \mathrm{C}$ to burn out the neat resin. The individual plies were separated and examined using a scanning electron microscope (SEM). The SEM was used to create the fractographs in Figures 4a-4d of the left notch-tip damage of an AS4/3501-6 panel, G4TAPEA. The damage displayed in these fractographs resulted from a load level of about $85 \%$ of the average ultimate failure load. The magnification is provided on each fractograph. The $\mathrm{x}$-ray radiograph of the specimen is provided for visual comparison of the two techniques for observing damage, $x$-ray radiography and ply fractography.

The first $45^{\circ}$ ply is shown in Figure $4 \mathrm{a}$ and the zinc iodide stain produced from the $\mathrm{x}$ ray procedure is a reliable indication of local delamination. The local delamination was traced and a schematic is shown to the right of the fractograph. Fiber fracture is visible in 
the $0^{\circ}$ and $-30^{\circ}$ plies in Figures $4 b$ and $4 c$, respecively. Again a schematic of the fiber fracture is shown to the right of the fractographs. At this load level, there was no fiber fracture in the $-45^{\circ},+45^{\circ},+30^{\circ}$ (Figure $4 d$ ), and of course $90^{\circ}$ plies. Fiber fracture was observed in the $+30^{\circ}$ plies in some of the other fractographic examinations. Local delamination was observed at the $-45^{\circ} / 45^{\circ}$ interface only. Therefore, for this panel at $85 \% \mathrm{~S}_{\mathrm{ult}}$, local delaminations are primarily surface ply delaminations. The extent and types of damage shown in Figure 4 is representative of what was observed in all of the other fractographic examinations.

\section{Isolation of Toughening Mechanisms}

The fracture behavior of the laminates in this study illustrates an obvious toughening behavior shown in the sequence of $\mathrm{x}$-ray radiographs of Figure 3 for the CNT panel. As the tensile load is monotonically increased, a zone of microcrack damage develops at the notch tip and progresses with increasing load. Examinations of the radiographs, and companion deply results performed for a few selected specimens, clearly show a well defined pattern of fiber fracture in the $0^{\circ}$ and $30^{\circ}$ plies that extends a significant distance from the notch before final translaminate fracture takes place. The pattern of fiber fracture is collinear with the notch length and resembles the crack extension due to stable tearing which ductile alloys exhibit prior to fracture $[21,22]$. In the case of a ductile alloy, stable crack growth is the result of crack growth resistance which is due to the effects of largescale metal plasticity. In the case of the composite, stable damage growth is the result of damage growth resistance which is due to two known toughening mechanisms: 1) the load redistribution (local stress relief) resulting from the microcracks and 2) the load transferred by the intact fibers of the off-axis plies that are adjacent to the principle load-carrying plies with broken fibers (ply bridging). Ply bridging is evident from examining the ply fractographs in Figure 4. Because the $+45^{\circ}$ ply in Figure 4 a has not fractured and there is no observable delamination in the $+45^{\circ} / 0^{\circ}$ ply interface, it seems likely that load was transferred from the fractured $0^{\circ}$ ply in Figure $4 \mathrm{~b}$ to the intact $+45^{\circ}$ ply in Figure $4 \mathrm{a}$. 
Similarly, it seems likely that load was transferred from the fractured $-30^{\circ}$ ply in Figure $4 \mathrm{c}$ to the intact $+30^{\circ}$ ply in Figure $4 \mathrm{~d}$. A progressive damage model has been developed that accounts for these toughening mechanisms and is discussed in the following paragraphs.

\section{PROGRESSIVE DAMAGE ANALYSIS}

A nonlinear damage dependent constitutive model has been implemented into a multipurpose finite element code [17] and a computational procedure has been developed to predict residual strength. The progressive damage methodology is applicable to any laminate stacking sequence and the finite element analysis uses quadrilateral shell elements to analyze general structural geometries.

\section{Nonlinear Damage-Dependent Constitutive Model}

A nonlinear, damage-dependent constitutive model was developed by Allen and Harris [12-14] to model the behavior of microcrack damage in brittle epoxy systems and has been extended to toughened polymer systems. The model predicts the formation of intraply matrix cracks and fiber fracture for monotonic tensile loading and for tension-tension fatigue (not discussed herein), the associated ply level stress and strain states, and the residual strength of laminates. In order to rigorously predict the initiation and growth of delamination, three-dimensional stress states such as those at the laminate free edges must be calculated. The analysis currently does not have this capability. The Allen-Harris model has an empirical relationship that can account for the effects of delaminations on load redistribution in a laminate. This empirical relationship requires the user to specify the location and extent of delamination. This approach does not contribute to the authors' goal to develop a damage dependent finite element analysis using only lamina material properties, therefore, delamination is not modeled in the present analysis. Complete details of the mathematical formulation and various aspects of the model are available in references [12-17] and will not be presented here.

The constitutive model uses internal state variables (ISV) to represent the average 
effects of local deformation due to the various modes of microcrack damage. This concept is called continuum damage mechanics. The constitutive model for a local volume element may be written as [12]

$$
\sigma_{i j_{L}}=\mathrm{Q}_{i j k l}\left\{\varepsilon_{k l}-\alpha_{k l}\right\}_{L}
$$

where $\sigma_{i j_{L}}$ are the locally averaged components of stress, $Q_{i j k l}$ are the ply-level reduced moduli, and $\varepsilon_{\mathrm{kl}_{\mathrm{L}}}$ are the locally averaged components of strain. The internal state variables, $\alpha_{\mathrm{kl}_{\mathrm{L}}}$, represent the local deformation effects of the various modes of damage. When the material is subjected to quasi-static (monotonic) loads, the incremental change of the internal state variable is assumed to be

$$
d \alpha_{k l_{L}}=\left\{\begin{array}{cl}
f\left(\varepsilon_{k l_{L}}, \beta, \gamma, \psi\right) & \text { if } \varepsilon_{k l_{L}} \geq \varepsilon_{k l_{c r i t}} \\
0 & \text { if } \varepsilon_{k l_{L}} \leq \varepsilon_{k l_{c r i t}}
\end{array}\right.
$$

where $\varepsilon_{\mathrm{kl}_{\text {crit }}}$ is the critical tensile failure strain and $\beta, \gamma$, and $\psi$ are scale factors that describe the load carrying capability of the material after the occurrence of mode I (opening mode) matrix cracking, fiber fracture, and mode II (shear mode) matrix cracking, respectively. The physical interpretation of equation (2) is as follows: as long as the strains in a material element (local volume element or finite element) are less than the critical strains, $\varepsilon_{\mathrm{kl}}$ crit , no damage exists and the internal state variables have a zero value. When the strains reach their critical value, the element is damaged and this damage is represented by an internal state variable whose value is proportional to the local strain. The proportionality is dependent on the scale factors $\beta, \gamma$, and $\psi$. Based on these assumptions, when fiber fracture, mode II matrix cracking, or mode I matrix cracking occur in a ply within an element, the longitudinal, shear, and transverse stresses for that ply in that element are

$$
\begin{aligned}
& \sigma_{11}=\gamma S_{\mathrm{cr}}^{\mathrm{X}} \\
& \sigma_{12}=\psi S_{\mathrm{cr}}^{\mathrm{xy}} \\
& \sigma_{22}=\beta S_{\mathrm{cr}}^{\mathrm{y}},
\end{aligned}
$$

where $S_{\mathrm{cr}}^{\mathrm{X}}, S_{\mathrm{cr}}^{\mathrm{xy}}$, and $S_{\mathrm{cr}}^{\mathrm{y}}$ are the lamina longitudinal, shear, and transverse critical strengths, respectively. Note that damaged elements are not removed. Instead, the value 
of the internal state variable in the damaged elements increases proportionately with strain such that equations (3), (4), and (5) are not violated.

\section{Progressive Damage and Residual Strength Methodology}

\section{Structural Analysis Algorithm}

The damage dependent constitutive equations (1) are substituted into the laminate resultant force and moment equations to produce damage dependent laminate resultant force and moment equations [23]. These equations are substituted into the plate equilibrium equations resulting in a set of governing differential equations which can be integrated against variations in the displacement components to produce a weak form of the damagedependent laminated-plate equilibrium equations $[17,23]$. By substituting displacement interpolation functions into the weak form of the plate equilibrium equations and following well known finite element procedures, the assembled equilibrium equations are obtained as

$$
[\mathrm{K}]\{\delta\}=\left\{\mathrm{F}_{\mathrm{A}}\right\}+\left\{\mathrm{F}_{\mathrm{D}}\right\}
$$

where $[\mathrm{K}]$ is the original global stiffness matrix, $\{\delta\}$ is the global displacement vector, $\left\{F_{A}\right\}$ is the applied force vector, and $\left\{F_{D}\right\}$ is the damage induced force vector. Since the effects of damage are represented as damage-induced force vectors on the right hand side of equation (6), the element stiffness matrix need not be recalculated as damage progresses as long as the nonlinearity in the load-deflection curve is not large.

The progression of damage is predicted by an iterative and incremental procedure outlined in the flow chart shown ir Figure 5. This entire progressive failure analysis scheme has been implemented into the finite element formulation in the NASA Computational Mechanics Testbed (COMET) [17] computer code. The first block of Figure 5 is a description of the information needed as model input (block numbers are shown in the right hand bottom corner of each block). Blocks 2 and 3 are COMET processors that calculate and assemble the elemental stiffness matrices and factor the global stiffness matrix. In block 4, the damage induced force vector for the current damage state is then combined with the applied force vector to update the global force vector [17]. Block 
4 is called the damage resultant force (DRF) processor [17] and is part of the damage dependency that was implemented into the finite element analysis. Using the updated global force vector, COMET solves for global displacements, $\{\delta\}$, in block 5 using equation (6).

The element stress resultants are calculated by COMET processors in block 6. The plylevel stresses, strains, and damage are calculated in block 7 using a processor called damage growth increment (DGI) and is the other part of the model's damage dependency that was implemented into the finite element analysis. The final computational result of processor DGI, block 8, is the updated damage state and post-processed ply-level stresses and strains. Processor DGI uses equations (1) and (2) to compute and update the damage state.

The equilibrated solution is obtained when the damage-induced force vector and the change in displacements become negligible. If the solution shows that equilibrium is established, then the next load increment is applied. If equilibrium is not established, then iteration is performed holding the loads at the current level. As the applied load approaches the catastrophic failure load, the number of iterations required to establish equilibrium increases. This is because the strains in the surrounding undamaged elements approach critical values. In the process of iteration, displacement increases lead to increases in strain levels in these elements and the strains may exceed the failure strains. Therefore, damage may grow from one iteration to the next. Eventually, as loads increase, a load level will be reached where equilibrium is unattainable. This value of load is defined to be the catastrophic failure load.

\section{Failure Mechanics}

The monotonic damage growth parameters $(\beta, \psi$, and $\gamma)$ can be complicated algebraic functions describing the complex behavior of load redistribution due to matrix cracking and fiber fracture. However, for the purpose of developing the framework for this progressive damage methodology, simple constants were chosen for the parameters. So for this 
analysis, the damage growth law parameters govern the load redistribution in a way that is similar to the ply discount method. It is not reasonable to assume a $100 \%$ load redistribution at the instant of failure for mode I matrix cracking and tensile fiber fracture. Therefore, a $90 \%$ load redistribution was assumed, i.e. the local ply stress is only $10 \%$ of the critical ply strength $(\beta=0.1$ and $\gamma=0.1)$. As the applied load increases, mode I matrix cracking and tensile fiber fracture internal state variables increase in proportion to the local strains. This results in a constant stress level (10\% of the critical ply strength) in the damaged plies, illustrated in Figures 6(a) and 6(b), with the load redistributing to the surrounding plies and elements.

Based on Iosipescu shear data [20], there is a shear strain $\left(\gamma_{12}^{\mathrm{o}}\right)$ where the behavior is no longer linear and becomes almost perfectly plastic. At this strain level, $\psi$ is equal to 1.0 to simulate elastic-perfectly plastic shear stress/strain behavior as illustrated in Figure 6c. This implies that as the applied load increases, the damaged ply carries $100 \%$ of the critical shear strength while the additional stress transfers to the surrounding plies and elements. When the shear strain becomes catastrophic $\left(\gamma_{12}^{\mathrm{cr}}\right), \psi$ is assumed to be equal to 0.1 . The load redistribution for shear is now similar to the case for mode I matrix cracking.

The material property descriptions required for the model include standard ply stiffness and strength data determined in the conventional manner for classical lamination theory [24]. Under monotonic tension loading, the model uses only the fiber failure strain and matrix failure strain determined from unidirectional laminate data to predict progressive damage and residual strength. These properties are listed in Table 2 for the three material systems investigated in this study. The model also uses matrix failure shear strain. Iosipescu shear data [20] was used to approximate the values of $\gamma_{12}^{\mathrm{o}}$ and $\gamma_{12}^{\mathrm{cr}}$ to be $1 \%$ and $10 \%$, respectively.

\section{Finite Element Analysis}

The $[\mp 45 / 0 / 90 / \mp 30 / \overline{0}]_{\mathrm{S}}$ laminate was modeled with ply thicknesses of $0.1828 \mathrm{~mm}$. In this two-dimensional analysis, symmetry boundary conditions ( $v=0$ on the $y=0$ 
centerline and $u=0$ on the $x=0$ centerline from the notch tip to the panel's edge) were used to model one-quarter of the panel as shown in Figure 7. Four node quadrilateral EX47 shell elements in the COMET code were used to model the panel.

Since the individual plies of the angle-ply laminate were modeled discretely, effects of the symmetry assumptions on the results were investigated. The results of modeling a complete $10.2 \mathrm{~cm}$ panel with a $2.54 \mathrm{~cm}$ notch were compared to the results of modeling one-quarter of the panel with quarter symmetry. Before damage initiation, the strain, stress, and displacements at the free edge and near the notch-tip differed by much less than one percent between the full model and the quarter symmetry model. Loads were then applied monotonically until catastrophic failure and the failure strengths differed by only three percent. Thus one-quarter panel models were used for all predictions reported herein.

The tensile loading is applied at increments of $35 \mathrm{~N} / \mathrm{cm}$ (2lb/in.). Load increment sensitivity was not an issue since the model predicted the same strength for two different loading increments, $35 \mathrm{~N} / \mathrm{cm}$ and $17.5 \mathrm{~N} / \mathrm{cm}$.

\section{Mesh Refinement Issues Related to the Center-Notch Geometry}

The notch was machined with an ultrasonic cutter which resulted in notches that did not have smooth radial notch-tips. The drawings in Figure 8 show two different finite element mesh configurations modeling the notch-tip, mesh 1 and mesh 2 . These drawings are not to scale.

The first notch-tip configuration, mesh 1 , has no radius and results in a stress singularity at the notch-tip. A finite element mesh refinement study was conducted for mesh 1 . The numerical results showed that very coarse meshes resulted in significantly over-predicted values of residual strength and very fine meshes significantly underpredicted the residual strength values, relative to the average experimental values. These results are as expected because solutions for mesh 1 do not converge with mesh refinement due to the stress singularity at the notch-tip. Therefore, the first ply failure load decreases

as the notch-tip element size decreases. The premature fiber fracture, represented by an 
internal state variable, results in a higher compliance and an artificially low residual strength prediction.

A mesh refinement study was performed for mesh 2 and a converged stress concentration and solution was obtained. However, very small elements were required to model the radius of the notch so the model consisted of a large number of elements. This resulted in a finite element model with large degrees of freedom and hence required more computer resources for the analysis. Furthermore, because of the very small elements surrounding the notch in mesh 2 , the notch-tip strains were much greater than in mesh 1 . As a result, damage initiated at a lower applied load level increasing the compliance and the computed rate of damage progression. For these reasons, the authors decided to use mesh 1 to understand the effect element size had on the residual strength predictions.

The strong dependence on element size exhibited by the residual strength predictions is probably due to the local volume averaging approach employed by the model to specify the values of the ISV damage parameters. The averaging procedure indirectly introduces a length-scale parameter into the damage representation. This is analogous to the point stress or average stress models proposed by Whitney and Nuismer $[25,26]$ which use the unnotched laminate strength and a characteristic distance to predict fracture. The length scale parameter was accounted for in this model by selecting a notch-tip element size that yielded residual strength predictions within a few percent of the experimental results for the $10.2 \mathrm{~cm}$ wide panel with the $2.54 \mathrm{~cm}$ notch. This notch-tip element size was then used in the analysis for all panel widths, notch sizes, and material systems.

\section{EXPERIMENTAL AND COMPUTATIONAL RESULTS}

\section{Residual Strength of Center-Notch Tension Panels}

Figure 9 presents the extent of damage predicted by the analytical model for the $91 \mathrm{~cm}$ wide AS4/938 panel. A dimensioned drawing of the center-notch panel is shown at the top left with a small box drawn around the notch-tip region that represents the approximate area 
covered by the mesh displayed to the right of the drawing. The mesh uses shaded elements, providing a damage contour, to represent the modeled damage at $88 \%$ of the predicted ultimate failure load. The damage contour in Figure 9(a) illustrates the ply-level fiber fracture in the elements near the notch-tip. Mode I and mode II matrix cracking are illustrated in Figures 9(b) and 9(c), respectively. An interesting observation of Figure 9(a) is that the $-45^{\circ}$ ply exhibits much less progression of fiber fracture than the $+45^{\circ} \mathrm{ply}$. This is a numerical result of using a strain failure criterion to initiate damage. If a uniaxial tensile load is applied to an unnotched composite laminate, $\varepsilon_{1}$ equals $\varepsilon_{2}$ for the $+45^{\circ}$ and $-45^{\circ}$ plies. If the laminate has a notch, then the resultant laminate shear force is no longer equal to zero, and $\varepsilon_{1}$ does not equal $\varepsilon_{2}$ within a $45^{\circ}$ ply. Instead, $\varepsilon_{1}$ of the $-45^{\circ}$ ply is equal to $\varepsilon_{2}$ of the $+45^{\circ} \mathrm{ply}$, and $\varepsilon_{2}$ of the $-45^{\circ} \mathrm{ply}$ is equal to $\varepsilon_{1}$ of the $+45^{\circ} \mathrm{ply}$. The result is as shown in Figure 9(a), fewer fibers in the $-45^{\circ}$ ply failed because $\varepsilon_{1}$ in the $-45^{\circ}$ ply barely exceeded the critical strain. These strains did eventually become critical as the applied load approached the load at which equilibrium was unattainable (previously defined as the catastrophic failure load).

These figures were drawn for an equilibrated solution and illustrate the capability in the analysis to model stable damage growth. Fiber fracture has extended nominally $2.7 \mathrm{~cm}$ from the notch-tip. Mode I and mode II matrix cracking has progressed to $3.2 \mathrm{~cm}$ and 3.0 $\mathrm{cm}$, respectively. Excluding delamination, the stable damage growth illustrated in these figures is qualitatively similar to what was observed in the experiments. There are elements with fractured plies adjacent to intact plies and mode I matrix cracking occurs in many more elements than the other modes of damage.

Stable damage growth is the result of damage growth resistance which is illustrated for the $91 \mathrm{~cm}$ wide AS4/938 panels in Figure 10 where the experimental R-curve is compared to the analytical predictions. A discussion on effective damage growth and the details of how to quantify damage growth resistance in an R-curve is provided in the Appendix. The model predicted a substantial amount of stable fiber fracture for the $91 \mathrm{~cm}$ wide panel. The 
trend of the analytical results is similar to the experimental R-curve. The R-curve is the average of the experimental data shown in the plot. The analytically predicted data points are represented by the dark filled circles. The predicted effective damage growth is approximately equal to the length of predicted fiber fracture. It is evident from this plot that the progressive damage methodology presented here predicts damage growth resistance well.

The residual strength predictions are illustrated in Figure 11 where the experimental bars are the average of the three replicate tests, with the high and low values indicated for each experimental entry in the bar chart. (The AS4/3501-6 and the AS4/8553-40 laminates with the 9 inch notch had only one experimental value. The other AS4/3501-6 laminates had only two experimental values). Most of the predictions are within $\pm 10 \%$ of the experimental average values. The overall experimental data trends are accurately predicted by the analytical methodology. Since there is no consistent overprediction or underprediction trend exhibited by the model results, the simple failure criteria for each damage mechanism appears to be reasonable for the tensile fracture tests reported herein.

The fracture of the center-notch geometry exhibits a panel width and notch size effect. This behavior is best observed by the plot of residual strength versus notch size shown in Figure 12. The experimental average values and the model predictions are compared to the classical linear elastic fracture mechanics (LEFM) results for the panel made of the AS4/938 material system. According to LEFM, for the same $(2 \mathrm{a} / \mathrm{W})$ ratio, the ultimate strength is inversely proportional to the square root of the half notch length. This data is plotted in Figure 12 as the solid line labeled LEFM and was obtained by determining the fracture toughness of the laminate from the residual strength of the smallest specimen with a $(2 \mathrm{a} / \mathrm{W})$ ratio equal to $1 / 4$. Notice that the experimental values for the $22.9 \mathrm{~cm}$ notch are about $45 \%$ higher than the LEFM based predictions. The progressive damage model correctly predicts this increase in the fracture strength. From these results, it is obvious that the finite element model predictions are more accurate than LEFM for wide panels where the fracture 
resistance effects are dominant. This size effect is produced by toughening mechanisms exhibited by the laminate and is correctly predicted by the progressive damage model.

\section{DISCUSSION OF COMPUTATIONAL RESULTS}

\section{Lamina Material Property Sensitivity}

A parametric study was conducted to examine the sensitivity of the predicted residual strength to the various ply level material properties used in the analysis. The results of several analytical case studies are reported in Tables 3 and 4 for the AS4/3501-6 material system since the largest over-predictions were made for this material system. The properties used in the baseline analysis are recorded in each table. The property that is changed in cases 1 through 5 are shown in italic and bold face font. For each case, only one property is different from the baseline properties. The resulting residual strength predictions are given at the bottom of the column.

Notice that in Table 3, a $10 \%$ decrease in $\mathrm{E}_{11}$ (case 1) results in a $13 \%$ decrease in strength. Furthermore, a 10\% decrease in the fiber fracture critical strain (case 5) results in an $11 \%$ decrease in residual strength. A $10 \%$ decrease in $\mathrm{E}_{22}, \mathrm{G}_{12}$, and $\varepsilon_{22}^{\mathrm{cr}}$ had an insignificant effect on residual strength. These are the expected results for the tensile fracture of a fiber dominated laminate. Case 1 and 2 of Table 4 show that one can vary the shear failing strains by $10 \%$ with little to no effect. However, if the shear strain is not used to initiate mode II matrix cracking as in case 3 of Table 4, the residual strength increases significantly by as much as $24 \%$ for the case reported. This is because the longitudinal strain in the fiber direction, $\varepsilon_{11}$, is dependent on the laminate resultant shear force which includes the effects of mode II matrix cracking. These results suggest the importance of accounting for mode II matrix cracking as well as fiber fracture, even though slight variations in the mode II matrix cracking criterion did not affect the analytical results.

Most of the analytical predictions fell within or very near the experimental data scatter as shown in Figure 11. Considering that the material properties may vary $\pm 10 \%$ 
depending on where and how they are obtained, the residual strength predictions agree well with the experimental values with the exceptions of the $10.16 \mathrm{~cm}$ and $91 \mathrm{~cm}$ wide AS4/3501-6 panels. Notice that the failure loads for these panels were lower than the failure loads for the AS4/938 panels. An inspection of the lamina material properties presented in Table 2 would lead to the conclusion that the AS4/3501-6 experimental failure loads should have been close to the AS4/8553-40 failure loads and greater than the AS4/938 failure loads. This was not the case. The material properties obtained from reference [18] appear to be somewhat different than the actual material properties for the laminates tested in this study.

\section{Effects of Delamination on the Residual Strength}

This progressive damage methodology currently does not have the capability to rigorously model delamination. However, the experimental observations made from the $\mathrm{x}$ ray radiographs and ply fractographs provided strong evidence that the delaminations were primarily surface ply delaminations and that fiber fracture was the dominant failure mechanism. It was also observed that accurate analytical predictions of residual strength were dependent primarily on the ability to model fiber fracture and mode II matrix cracking. Based on these experimental and numerical observations, the authors believe delamination was not a dominant failure mechanism for these laminates and that this analysis did not need to account for the delaminations.

\section{CONCLUDING REMARKS}

An experimental investigation of translaminate fracture was conducted and a residual strength prediction capability was developed using a progressive damage methodology. An experimental characterization of several composite materials systems revealed occurrences of damage growth resistance. Fractographic examinations led to the observation that this damage growth resistance could be due to ply bridging, defined in this study as fractured fibers of one ply bridged by intact fibers of an adjacent ply. The Allen-Harris nonlinear constitutive model was used in a finite element code to model the matrix cracking and fiber 
fracture that results from the notch-tip stresses in center-notch tension composite panels. The fiber failure criterion used to model the progression of fiber fracture redistributes the load so that when the ply level strain in an element of the finite element model exceeds the fiber failure strain, the elemental ply load carrying capability is only $10 \%$ of the failure strength. This type of fiber failure criterion resembles the ply discount method. However, the mathematical framework exists such that any failure criterion can be implemented into the model to simulate the nonlinear behavior due to any type or mode of damage.

Mesh refinement studies illustrated the difficulty in modeling notch-tip damage for very thin notches with notch-tips that were not smooth radial notch-tips. This study revealed that for the center-notch configuration, the local volume averaging of the internal state variables introduced a length scale effect. The notch-tip element size was determined using the results from the $10.16 \mathrm{~cm}$ wide panel with the $2.54 \mathrm{~cm}$ long notch. This element size was used in all of the other panel and notch sizes to predict residual strengths to within \pm $10 \%$ for most cases. In addition, a panel width size effect was observed in the experiments and the model was able to accurately predict that effect. From these observations it was concluded that the progressive damage model can predict translaminate fracture more accurately than linear elastic fracture mechanics using only material properties determined from the standard unidirectional laminate and Iosipescu shear test methods.

\section{REFERENCES}

[1] Poe, C.C., Jr., "A Unifying Strain Criterion for Fracture of Fibrous Composite Laminates," Engineering Fracture Mechanics, Vol. 17, No. 2, pp. 153-171, 1983.

[2] Harris, C.E. and Morris, D.H., "A Fractographic Investigation of the Influence of Stacking Sequence on the Strength of Notched Laminated Composites," Fractography of Modern Engineering Materials: Composites and Metals, ASTM STP 948, J.E. Masters and J.J. Au, Eds., American Society for Testing and Materials, Philadelphia, 1987, pp.131-153.

[3] Harris, C.E. and Morris, D.H.,"On the Use of Crack-Tip-Opening Displacement to Predict the Fracture Strength of Notched Graphite/Epoxy Laminates," Experimental Mechanics, Vol. 25, No. 2, June 1985. 
[4] Poe, C.C., Jr., Harris, C.E., and Morris, D.H., "Surface Crack Analysis Applied to Impact Damage in a Thick Graphite/Epoxy Composite," SurfaceCrack Growth: Models, Experiments, and Structures, ASTM STP 1060,

W.G. Reuter, J.H. Underwood, and J.C. Newman, Jr., Eds., American Society for Testing and Materials, Philadelphia, 1990, pp. 194-212.

[5] Poe, C.C., Jr., Harris, C.E., Coats, T.W., and Walker, T.H., "Tension Strength with Discrete Source Damage," Proceedings of the Fifth NASA/DOD Advanced Composites Technology Conference, CP 3294, Vol. I, Part I, Seattle, Washington, Aug. 1994, pp. 369-438.

[6] Chamis, C.C., Murthy, P.L.N., and Minnetyan, L., "Structural Behavior of Composites with Progressive Fracture," J. of Reinforced Plastics and Composites, Vol. 11, April 1992, pp. 413-442.

[7] Talreja, R., "A Continuum Mechanics Characterization of Damage in Composite Materials," Proc. R. Soc. London, Vol. 399A, 1985, pp. 126-216.

[8] Talreja, R., "Residual Stiffness Properties of Cracked Composite Laminate", Advances in Fracture Research, Proc. Sixth Int. Conf. De Fracture, New Delhi, India, Vol. 4, 1985, pp. 3013-3019.

[9] Ladeveze, P., "A Damage Computational Method for Composite Structures," Computers and Structures, Vol. 44, No. 1/2, 1992, pp. 79-87.

[10] Chang, K-Y, Sheng, L., and Chang, F-K, "Damage Tolerance of Laminated Composites Containing an Open Hole and Subjected to Tensile Loadings," J. of Composite Materials, Vol. 25, March 1991, pp. 274-301.

[11] Chang, F-K and Chang, K-Y, "A Progressive Damage Model for Laminated Composites Containing Stress Concentrations," J. of Composite Materials, Vol. 21, Sept. 1987, pp. 834-855.

[12] Allen, D.H., Groves, S.E., and Harris, C.E., "A Cumulative Damage Model for Continuous Fiber Composite Laminates with Matrix Cracking and Interply Delamination," Composite Materials: Testing and Design ( $8^{\text {th }}$ Conference), ASTM STP 972, J.D. Whitcomb, Ed., American Society for Testing and Materials, Philadelphia, 1988, pp. 57-80.

[13] Lee, J.W., Allen, D.H., Harris, C.E., "Internal State Variable Approach for Predicting Stiffness Reductions in Fibrous Laminated Composites with Matrix Cracks," J. of Composite Materials, Vol. 23, Dec. 1989, pp. 1273-1291.

[14] Harris, C.E. and Allen, D.H., "A Continuum Damage Model of Fatigue-Induced Damage in Laminated Composites," SAMPE Journal, July/August 1988, pp. 4351.

[15] Lo, D.C., Allen, D.H., and Harris, C.E.; "A Continuum Model for Damage Evolution in Laminated Composites," Inelastic Deformation of Composite Materials, G.J. Dvorak, ed., Springer -Verlag, 1990, pp. 549-561. 
[16] Coats, T.W. and Harris, C.E., "Experimental Verification of a Progressive Damage Model for IM7/5260 Laminates Subjected to Tension-Tension Fatigue," J. of Composite Materials, Vol. 29, No. 3, 1995, pp. 280-305.

[17] Lo, D.C., Coats, T.W., Harris, C.E., and Allen, D.H., "Progressive Damage Analysis of Laminated Composite (PDALC) (A Computational Model Implemented in the NASA COMET Finite Element Code)," National Aeronautics and Space Administration Technical Memorandum 4724, August 1996.

[18] Lagace, P.A., Bhat, N.V., and Gundogdu, A., "Response of Notched Graphite/Epoxy and Graphite/Peek Systems," Composite Materials: Fatigue and Fracture, Fourth Volume, ASTM STP 1156, W.W. Stinchcomb and N.E. Ashbaugh, Eds., American Society for Testing and Materials, Philadelphia, 1993, pp. 55-71.

[19] Scholz, D.B., Dost, E.F., and Flynn, B.W., "Advanced Technology Composite Fuselage - Materials and Processes," National Aeronautics and Space Administration Contractor Report 4731, 1995.

[20] Coquill, S.L. and Adams, D.F., "Mechanical Properties of Several Neat Polymer Matrix Materials and Unidirectional Carbon Fiber-Reinforced Composites," National Aeronautics and Space Administration Contractor Report 181805, April 1989.

[21] Dawicke, D. S., J. C. Newman, Jr., M. A. Sutton, and B. E. Amstuz, "Influence of crack history on the stable tearing behavior of a thin-sheet material with multiple cracks," FAA/NASA International Symposium on Advacned Structural Integrity Methods for Airframe Durability and Damage Tolerance, NASA CP 3274, Charles E. Harris, editor, National Aeronautics and Space Administration, Washington, D.C., September 1994, pp. 193-212.

[22] deWit, R., R. J. Fields, L. Mordfin, S. R. Low, and D. Harne, "Fracture Behavior of Large-Scale Thin-Sheet Aluminum Alloy," FAA/NASA International Symposium on Advacned Structural Integrity Methods for Airframe Durability and Damage Tolerance, NASA CP 3274, Charles E. Harris, editor, National Aeronautics and Space Administration, Washington, D.C., pp. 963-984.

[23] Buie, K.D., "A Finite Element Model for Laminated Composite Plates with Matrix Cracks and Delaminations," Thesis, Texas A\&M University, December, 1988.

[24] Jones, Robert, M., "Mechanics of Composite Materials," Hemisphere Publishing Corporation, 1975.

[25] Whitney, J.M. and Nuismer, R.J.,"Stress Fracture Criteria for Laminated Composites Containing Stress Concentrations," J. Composite Materials, Vol. 8, pp. 253-265, 1974.

[26] Nuismer, R.J. and Whitney, J.M.,"Uniaxial Failure of Composite Laminates Containing Stress Concentrations," Fracture Mechanics of Composites, ASTM STP 593, American Society of Testing and Materials, pp. 117-142, 1975.

[27] Tada, H., Paris, P.C., and Irwin, G.R., "The Stress Analysis of Cracks Handbook," Del Research Corp., St. Louis, MO., 1973. 
Table 1 Summary of Experimental Test Matrix

\begin{tabular}{|l|l|c|c|c|c||}
\hline Material & $\begin{array}{l}\text { Specimen } \\
\text { Names }\end{array}$ & $\begin{array}{l}\text { aThickness }(\mathrm{t}), \\
\mathrm{mm}\end{array}$ & $\begin{array}{l}\text { Width (w), } \\
\mathrm{cm}\end{array}$ & $\begin{array}{l}\text { Length (L), } \\
\mathrm{cm}\end{array}$ & $\begin{array}{c}\text { Notch Length } \\
\left(2 \mathrm{a}_{\mathrm{o}}\right), \mathrm{cm}\end{array}$ \\
\hline AS4/8553-40 & A10-A13 & 2.62 & 2.54 & 28 & unnotched \\
(Panel AK1) & A3-A5 & 2.62 & 10.16 & 46 & 1.27 \\
tow-placed & B2-B6 & 2.62 & 10.16 & 46 & 2.54 \\
& A1,A2,B1 & 2.79 & 30.5 & 86 & 7.62 \\
& AK1 & $\mathrm{b}_{2.67}$ & 91 & 230 & 22.86 \\
AS4/938 & C10-C13 & 2.36 & 2.54 & 28 & unnotched \\
(Panel AK5A) & C3-C5 & 2.36 & 10.16 & 46 & 1.27 \\
tow-placed & D2-D6 & 2.36 & 10.16 & 46 & 2.54 \\
& C1,C2,D1 & 2.41 & 30.5 & 86 & 7.62 \\
& AK5A & $\mathrm{b}_{2.39}$ & 91 & 230 & 22.86 \\
AS4/938 & E10-E13 & 2.36 & 2.54 & 28 & unnotched \\
(Panel AK5B) & E3-E5 & 2.31 & 10.16 & 46 & 1.27 \\
tow-placed & F2-F6 & 2.31 & 10.16 & 46 & 2.54 \\
& E1,E2,F1 & 2.29 & 30.5 & 86 & 7.62 \\
& AK5B & b2.31 & 91 & 230 & 22.86 \\
& & & & & \\
AS4/3501-6 & G12-G18 & 2.36 & 2.54 & 28 & unnotched \\
(Panel TAPEA) & G3-G5 & 2.36 & 10.16 & 46 & 1.27 \\
Tape Prepreg & H2-H6 & 2.36 & 10.16 & 46 & 2.54 \\
& G1,G2,H1 & 2.36 & 30.5 & 86 & 7.62 \\
& TAPEA & b2.36 & 91 & 230 & 22.86 \\
\hline
\end{tabular}

a Stacking sequence for all panels $[\overline{+} 45 / 0 / 90 / \bar{\mp} 30 / \overline{0}]_{\mathrm{s}}$

b Average of above thicknesses since the smaller specimens were cut from the $91 \mathrm{~cm}$ wide panel after fracture test. 


\section{Table 2 Lamina Material Properties}

\begin{tabular}{||c|c|c|c|c|c|c|c||c|c||}
\hline Material & $\begin{array}{c}\mathrm{E}_{11} \\
(\mathrm{GPa})\end{array}$ & $\begin{array}{c}\mathrm{E}_{22} \\
(\mathrm{GPa})\end{array}$ & $\begin{array}{c}\mathrm{G}_{12} \\
(\mathrm{GPa})\end{array}$ & $\begin{array}{c}v_{\mathrm{f}}^{*} \\
(\%)\end{array}$ & $v_{12}$ & $\begin{array}{c}\varepsilon_{\mathrm{cr}}^{90} \\
(\%)\end{array}$ & $\begin{array}{c}\varepsilon_{\mathrm{cr}}^{0} \\
(\%)\end{array}$ & $\begin{array}{c}\gamma_{12}^{\mathrm{o}^{* *}} \\
(\%)\end{array}$ & $\begin{array}{c}\gamma_{12}^{\mathrm{cr} *} \\
(\%)\end{array}$ \\
\hline $\mathrm{a}_{\mathrm{AS} 4 / 8553-40}$ & 135.8 & 9.03 & 4.48 & 58.2 & 0.34 & 0.87 & 1.56 & 1.00 & 10.00 \\
${ }^{\mathrm{a}} \mathrm{AS} 4 / 938$ & 135.1 & 9.38 & 4.96 & 57.2 & 0.32 & 0.50 & 1.48 & 1.00 & 10.00 \\
$\mathrm{~b}_{\mathrm{AS} 4 / 3501-6}$ & 137.9 & 9.38 & 6.00 & 60.3 & 0.28 & 0.50 & 1.50 & 1.00 & 10.00 \\
\hline
\end{tabular}

a $\mathrm{E}_{11}, \mathrm{E}_{22}, \mathrm{G}_{12}, v_{12}, \varepsilon_{\mathrm{cr}}^{90}$, and $\varepsilon_{\mathrm{cr}}^{0}$ measured by Boeing and reported in reference [19].

b $\quad E_{11}, E_{22}, G_{12}, v_{12}, \varepsilon_{c r}^{90}$, and $\varepsilon_{c r}^{0}$ measured by Lagace et al. and reported in reference [18].

* $\quad v_{\mathrm{f}}$ was measured by the authors using a small sample of the $91 \mathrm{~cm}$ wide panels after the fracture tests.

** $\quad \gamma_{12}^{o}$ and $\gamma_{12}^{\mathrm{cr}}$ are approximations from Iosipescu shear test data reported in reference [20]. 
Table 3 - AS4/3501-6 Material Property Sensitivity Study, $\mathrm{W}=10.16 \mathrm{~cm}$ and $2 \mathrm{a}_{0}=2.54 \mathrm{~cm}$

\begin{tabular}{|c|c|c|c|c|c|c|}
\hline Properties & Baseline & Case 1 & Case 2 & Case 3 & Case 4 & Case 5 \\
\hline $\mathrm{E}_{11}$ & $137.9 \mathrm{GPa}$ & $\mathbf{1 2 4 . 1} \mathbf{G P a}$ & $137.9 \mathrm{GPa}$ & $137.9 \mathrm{GPa}$ & $137.9 \mathrm{GPa}$ & $137.9 \mathrm{GPa}$ \\
$\mathrm{E}_{22}$ & $9.38 \mathrm{GPa}$ & $9.38 \mathrm{GPa}$ & $8.41 \mathrm{GPa}$ & $9.38 \mathrm{GPa}$ & $9.38 \mathrm{GPa}$ & $9.38 \mathrm{GPa}$ \\
$\mathrm{G}_{12}$ & $6.00 \mathrm{GPa}$ & $6.00 \mathrm{GPa}$ & $6.00 \mathrm{GPa}$ & $5.38 \mathrm{GPa}$ & $6.00 \mathrm{GPa}$ & $6.00 \mathrm{GPa}$ \\
$v_{12}$ & 0.28 & 0.28 & 0.28 & 0.28 & 0.28 & 0.28 \\
$\mathrm{cr}$ & $0.50 \%$ & $0.50 \%$ & $0.50 \%$ & $0.50 \%$ & $\mathbf{0 . 4 5 \%}$ & $0.50 \%$ \\
$\varepsilon_{22} \mathrm{r}$ & $1.50 \%$ & $1.50 \%$ & $1.50 \%$ & $1.50 \%$ & $1.50 \%$ & $1.35 \%$ \\
$\varepsilon_{11}$ & $72.1 \mathrm{kN}$ & $65.0 \mathrm{kN}$ & $72.1 \mathrm{kN}$ & $72.1 \mathrm{kN}$ & $72.1 \mathrm{kN}$ & $65.9 \mathrm{kN}$ \\
\hline Predicted & $(+7 \%$ & $(+20 \%$ & $(+20 \%$ & $(+20 \%$ & $(+9 \%$ \\
Residual & $(+20 \%$ & Exp. & Exp. & Exp. & Exp. & Exp. \\
Strength & Exp. & Avp & Average $)$ & Average $)$ & Average) & Average) \\
\hline
\end{tabular}

Table 4 - AS4/3501-6 Shear Failure Strain Sensitivity Study, $\mathrm{W}=10.16 \mathrm{~cm}$ and $2 \mathrm{a}_{0}=2.54 \mathrm{~cm}$

\begin{tabular}{|c|c|c|c|c|}
\hline Properties & Baseline & Case 1 & Case 2 & Case 3 \\
\hline$\gamma_{12}^{\mathrm{o}}$ & 1.00 & $\mathbf{1 . 1 0}$ & 1.00 & not used \\
$\gamma_{12}^{\mathrm{cr}}$ & 10.00 & 10.00 & $\mathbf{1 1 . 0 0}$ & not used \\
\hline Predicted & $72.1 \mathrm{kN}$ & $73.4 \mathrm{kN}$ & $72.1 \mathrm{kN}$ & $86.8 \mathrm{kN}$ \\
Residual & $(+20 \%$ & $(+22 \%$ & $(+20 \%$ & $(+44 \%$ \\
Strength & $\begin{array}{c}(+20)^{2} \\
\text { Average })\end{array}$ & $\begin{array}{c}\text { Experimental } \\
\text { Average })\end{array}$ & $\begin{array}{c}\text { Experimental } \\
\text { Average })\end{array}$ & $\begin{array}{c}\text { Experimental } \\
\text { Average })\end{array}$ \\
\hline
\end{tabular}




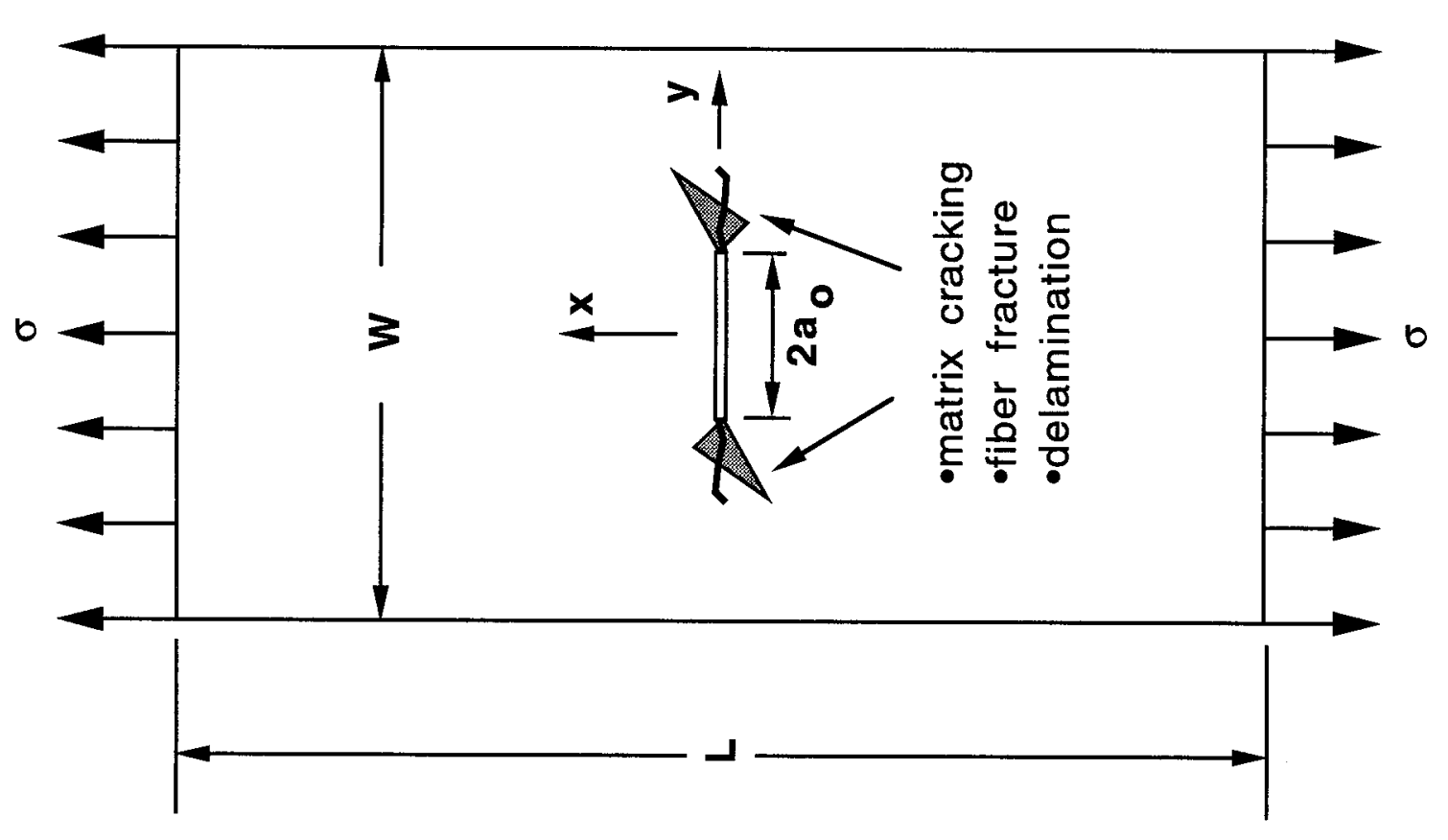

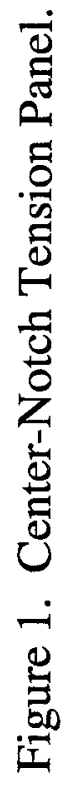




\section{AS4 / $938 \quad(\mp 45 / 0 / 90 / \mp 30 / \overline{0})_{S}$}

Far-field strain $=0.00205$

(89.6\% of failure)

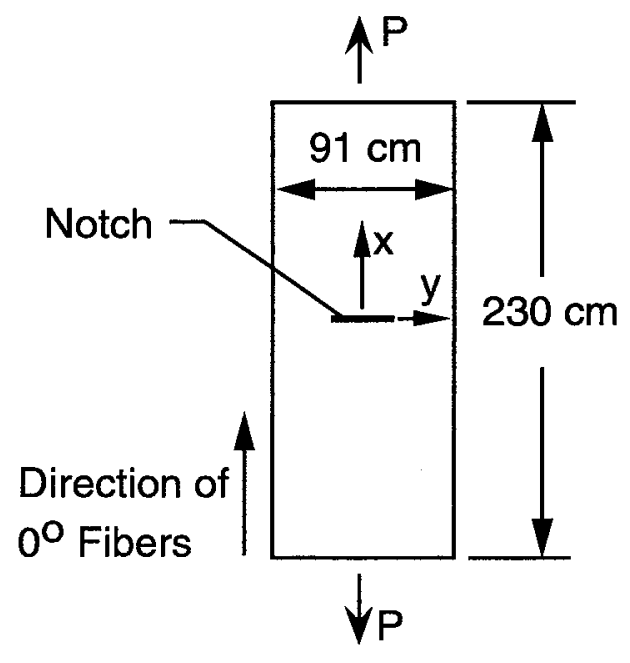

Notch Dimensions $22.9 \mathrm{~cm}$ long $0.05 \mathrm{~cm}$ wide
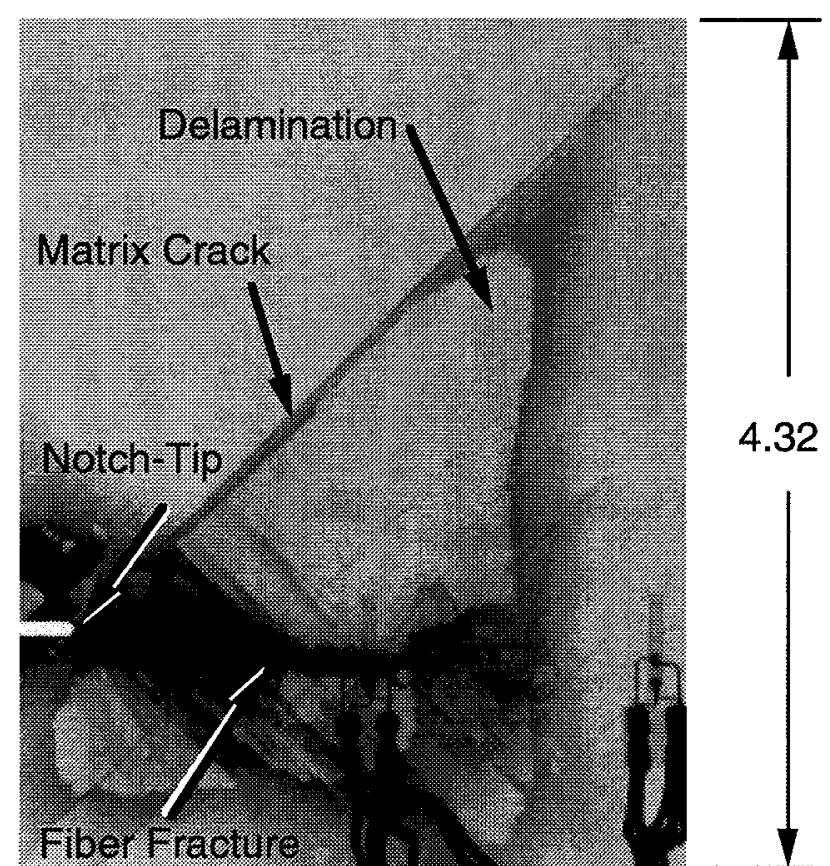

$4.32 \mathrm{~cm}$

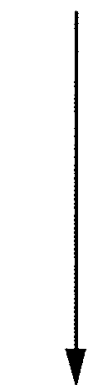

$3.40 \mathrm{~cm}$

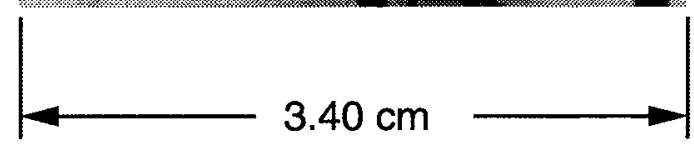

RIGHT NOTCH-TIP

Figure 2. Notch-Tip Damage Due to an Applied Tensile Load on an AS4/938 Composite Laminate. 


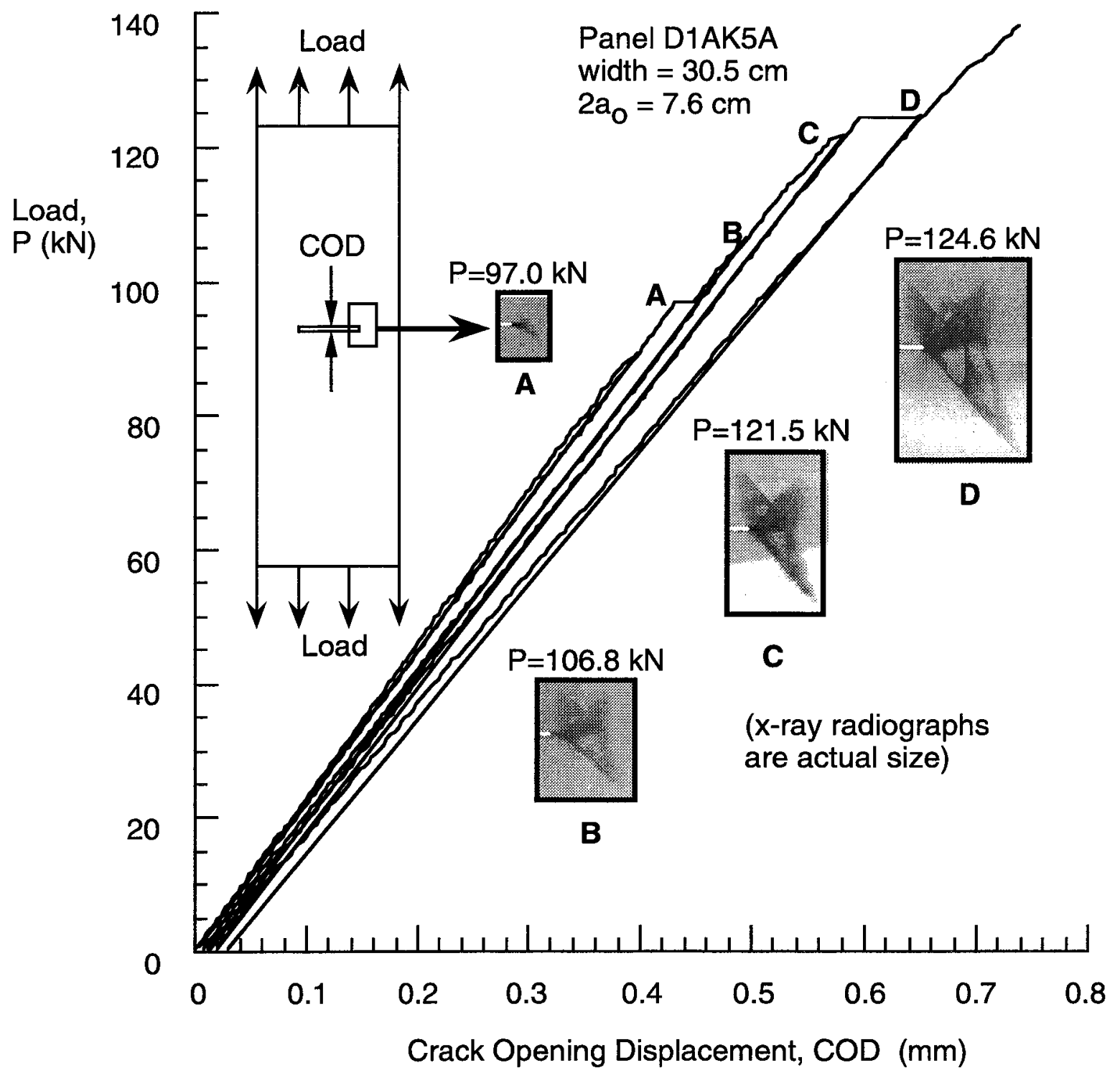

Figure 3. Load vs. COD Plot for Panel D1AK5A. 


\section{Panel G4TAPEA AS4/3501-6 $[\mp 45 / 0 / 90 / \mp 30 / \overline{0}]_{S} \quad 85 \%$ S $_{\text {ult }}$}

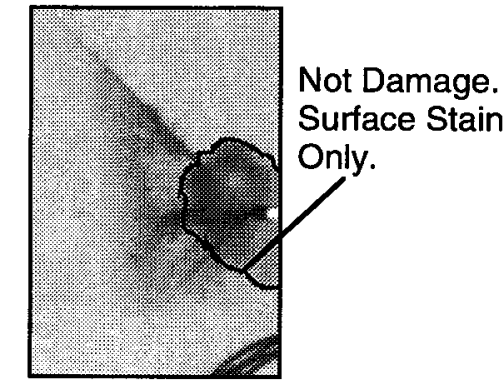

x-ray radiograph magnification: 2

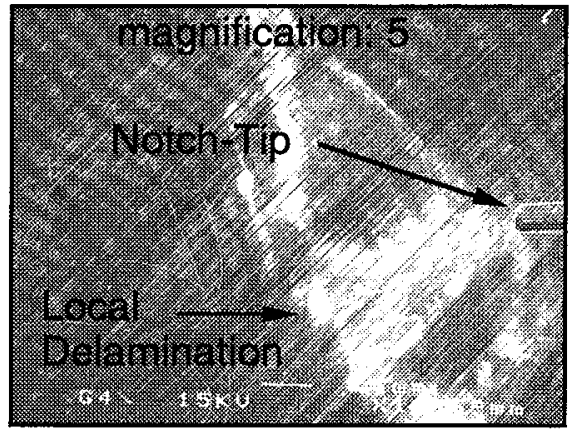

(a) $1^{\text {st }} 45^{\circ}$ ply, $-45 / 45$ interface
Local

Delamination

Notch
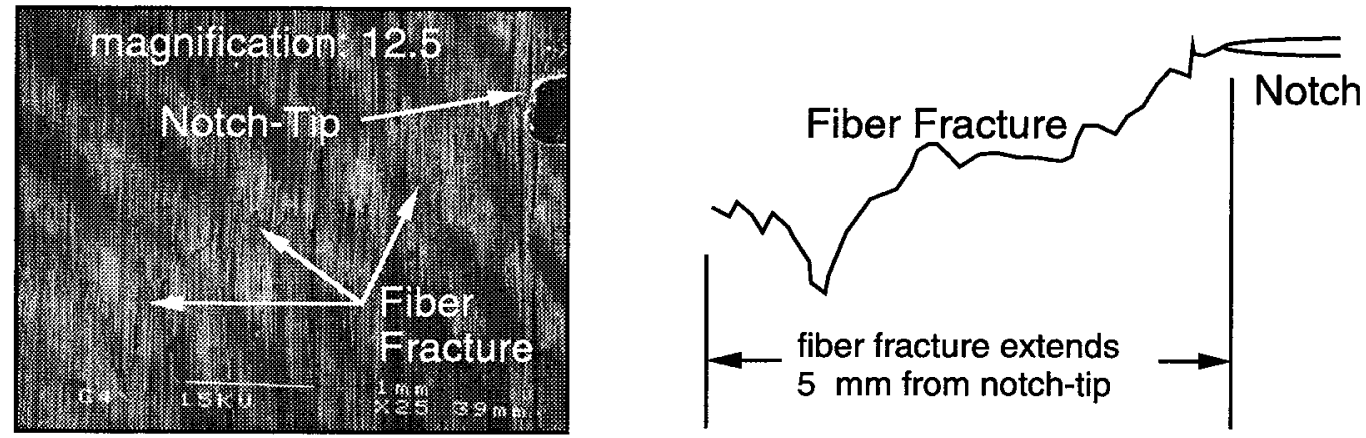

(b) $1^{\text {st }} 0^{\circ}$ ply, $45 / 0$ interface
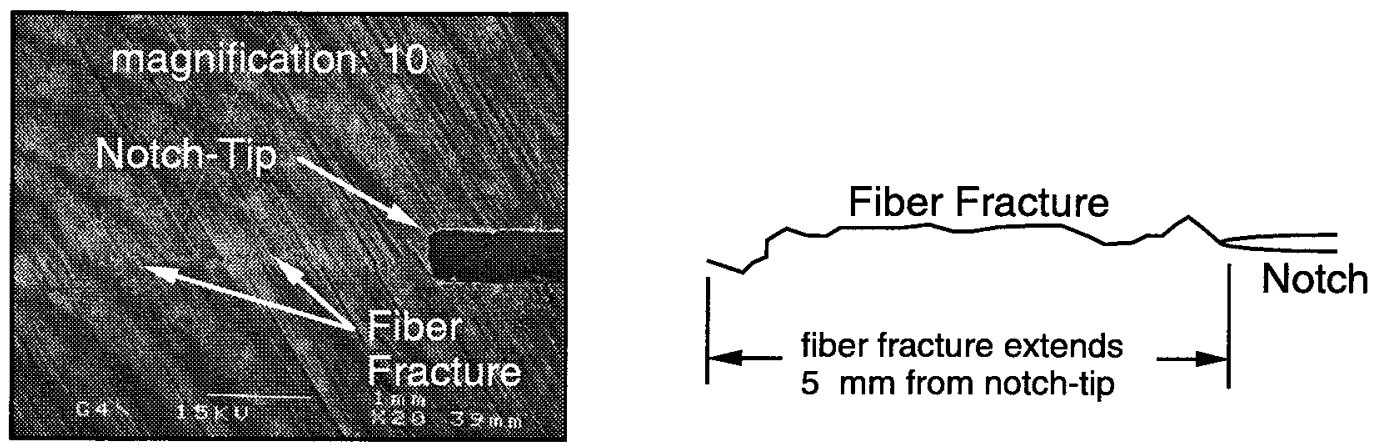

(c) $1^{\text {st }}-30^{\circ}$ ply, $90 /-30$ interface

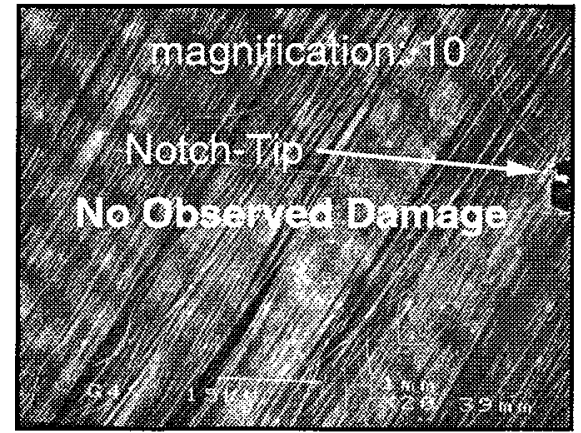

(d) $1^{\text {st }} 30^{\circ}$ ply, $-30 / 30$ interface

Figure 4. Typical Notch-Tip Damage of the Center-Notch Tension Panels. 


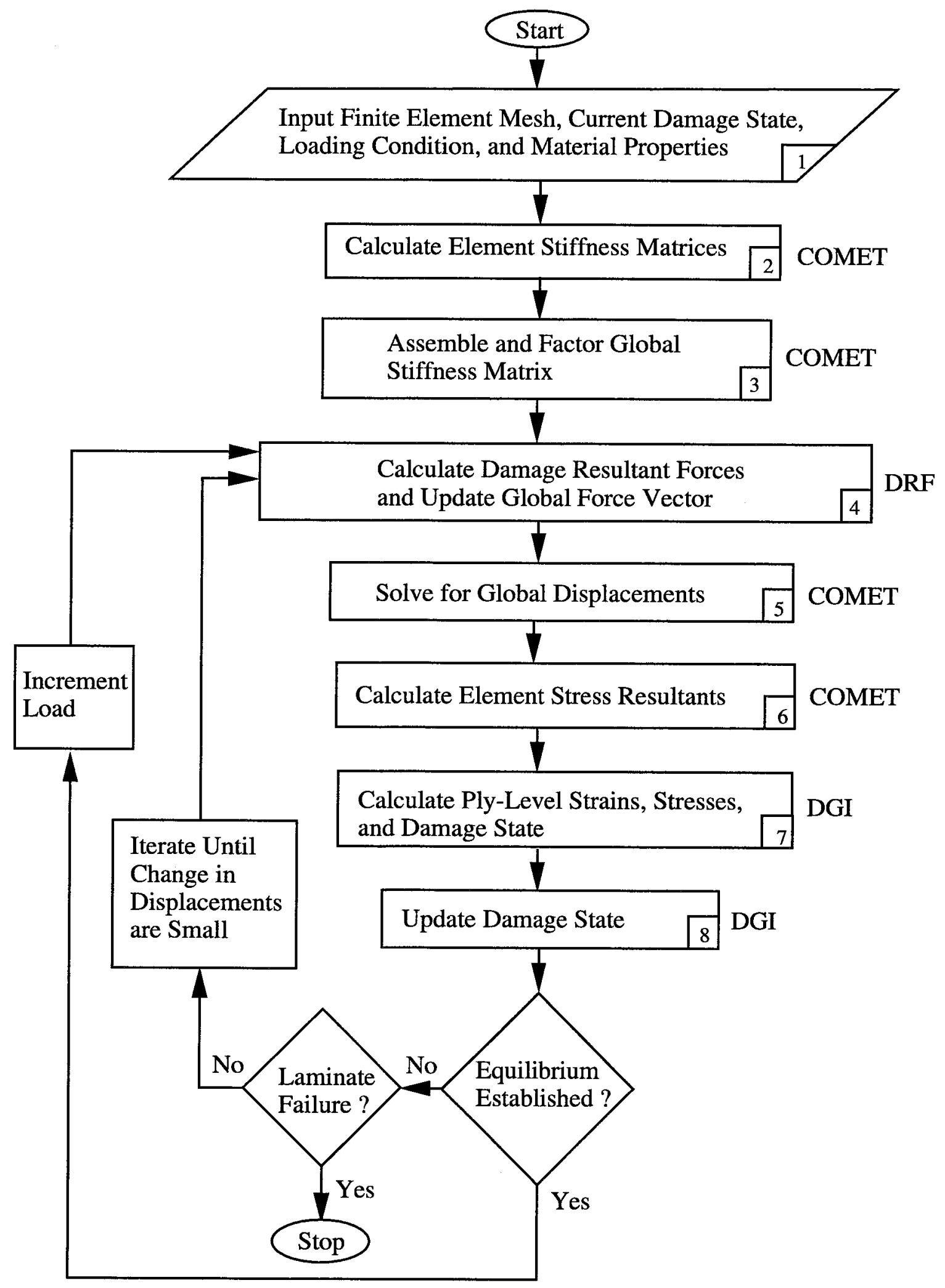

Figure 5. Progressive Failure Analysis. 


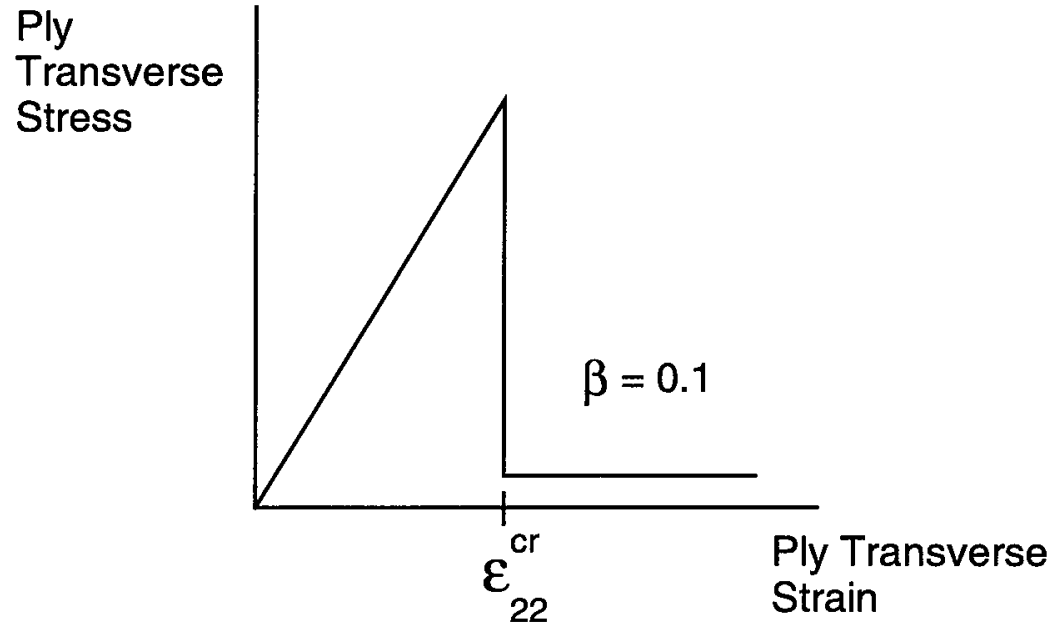

(a)

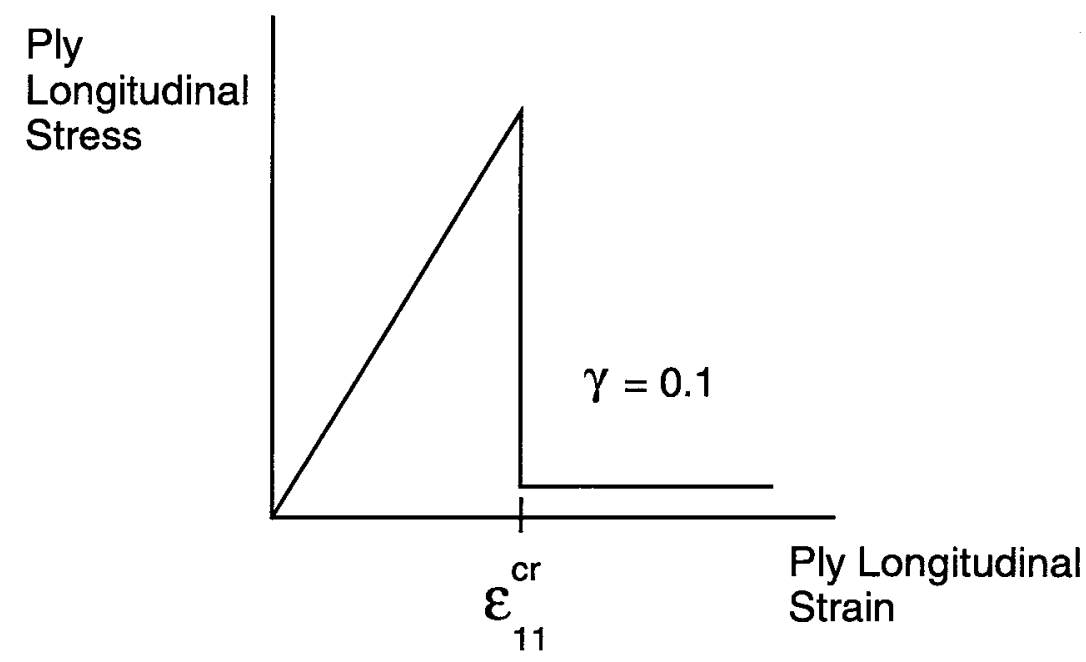

(b)

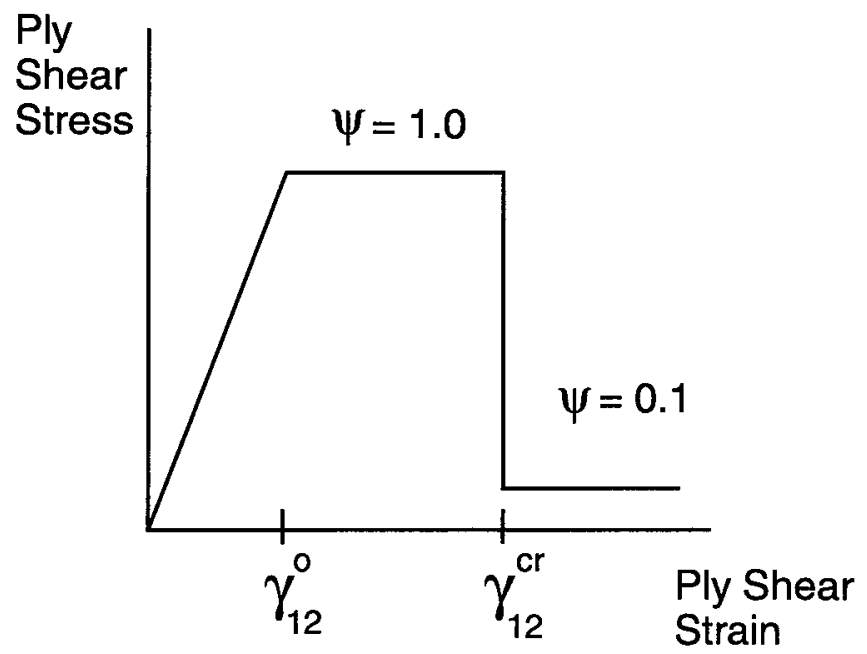

(c)

Figure 6. Failure Criteria Used in Progressive Damage Analysis. 


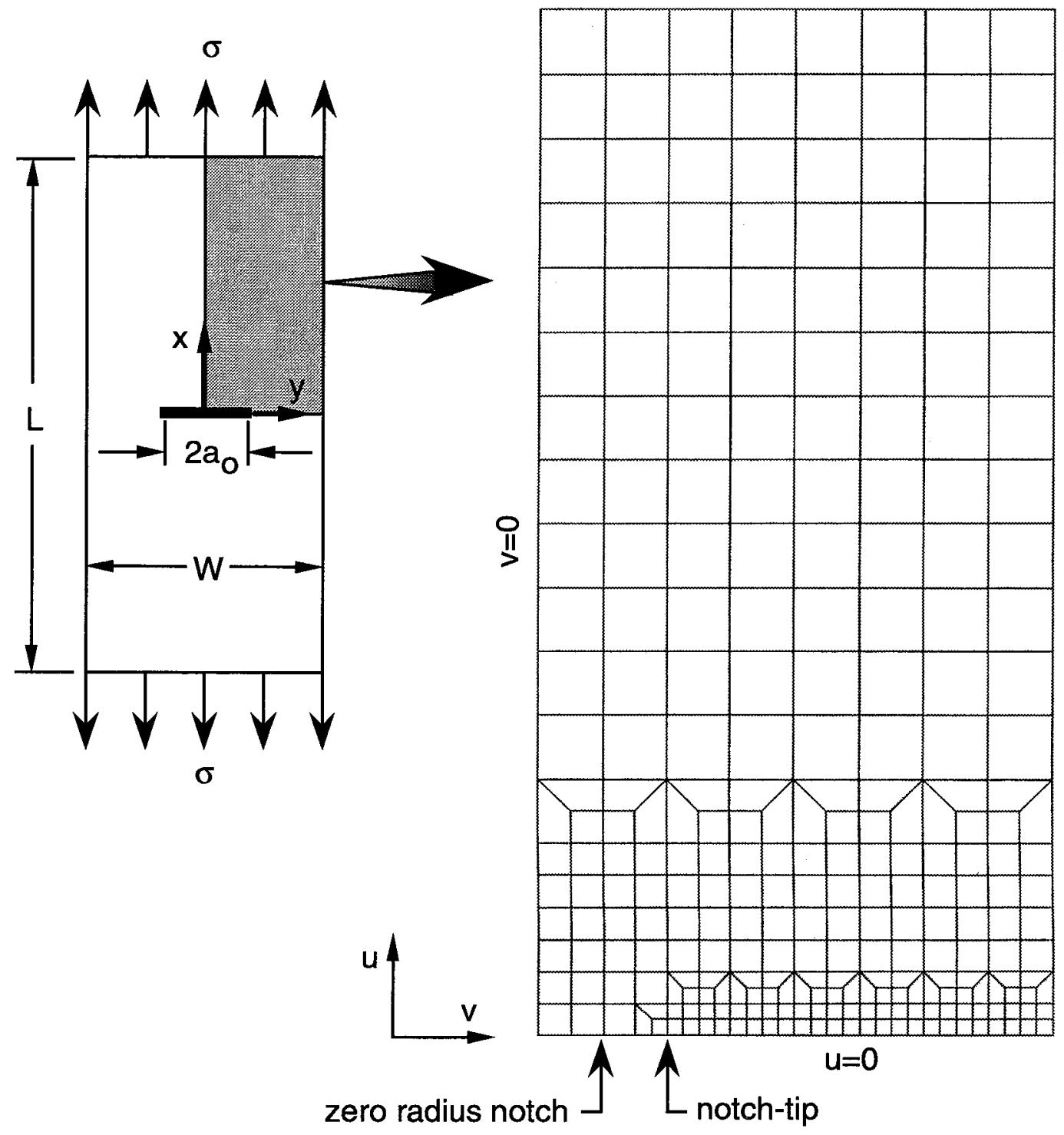

Figure 7. Finite Element Mesh of the Center-Notch Tension Panel. 


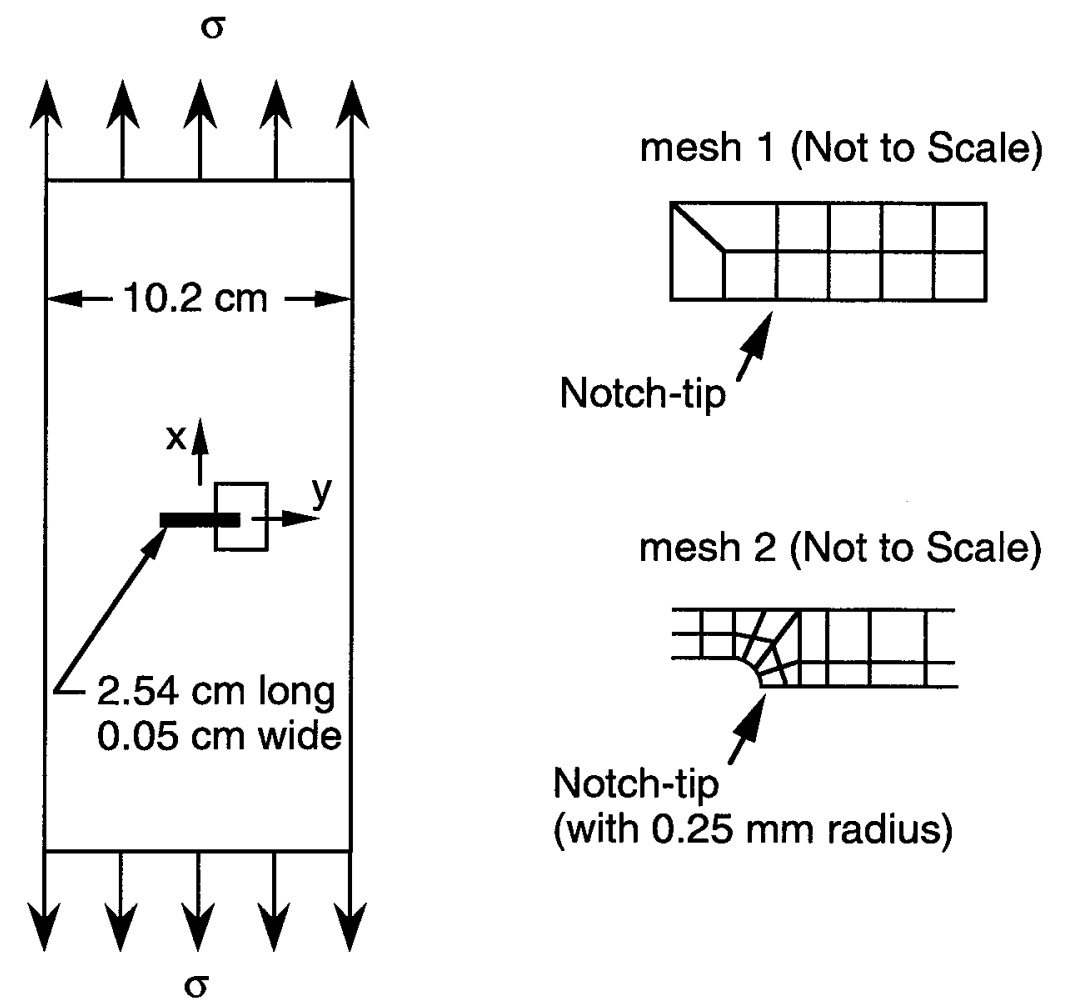

Figure 8. Mesh Refinement and Variations in Notch-Tip Geometry. 

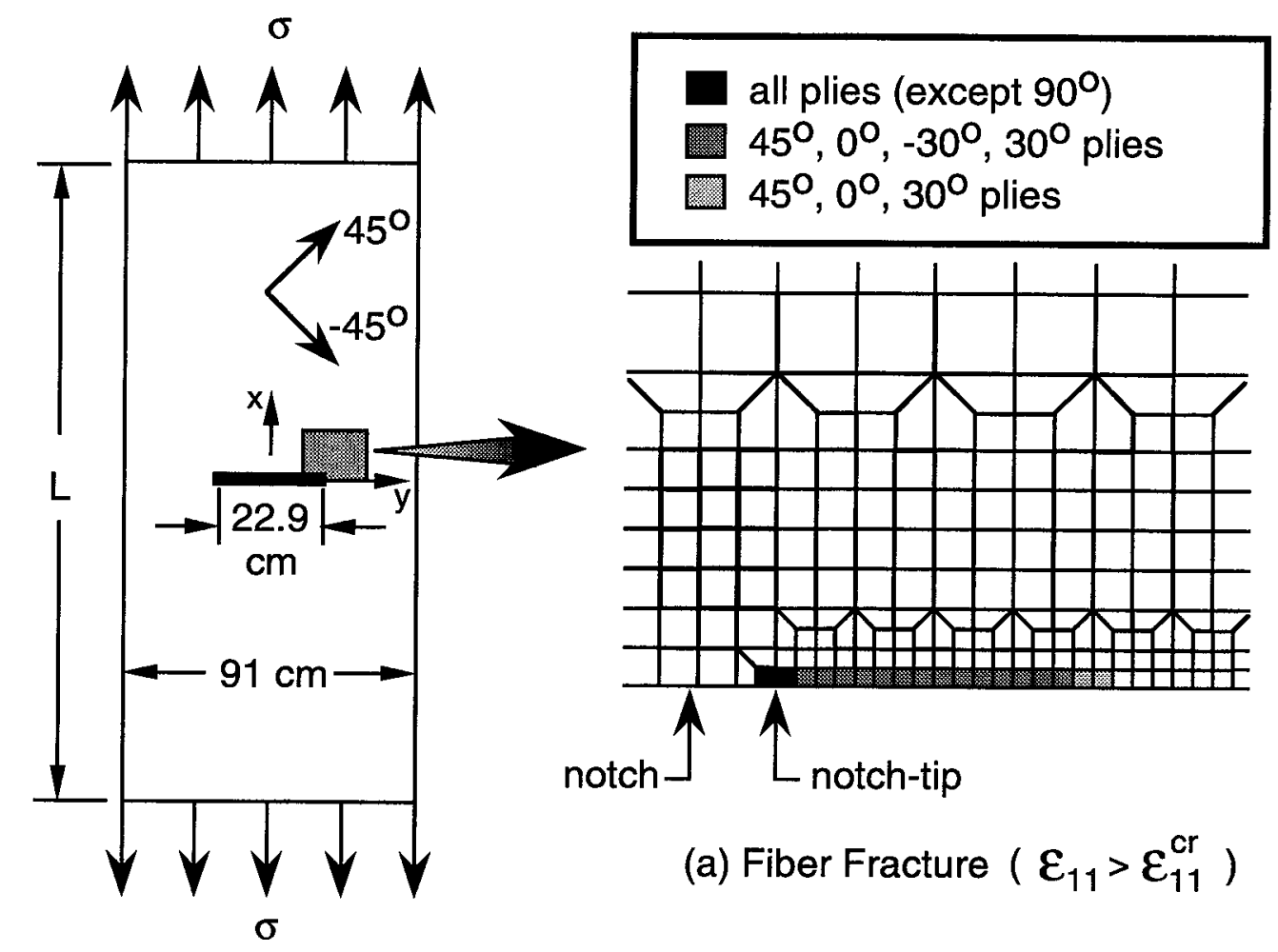

(a) Fiber Fracture $\left(\varepsilon_{11}>\varepsilon_{11}^{\mathrm{cr}}\right)$
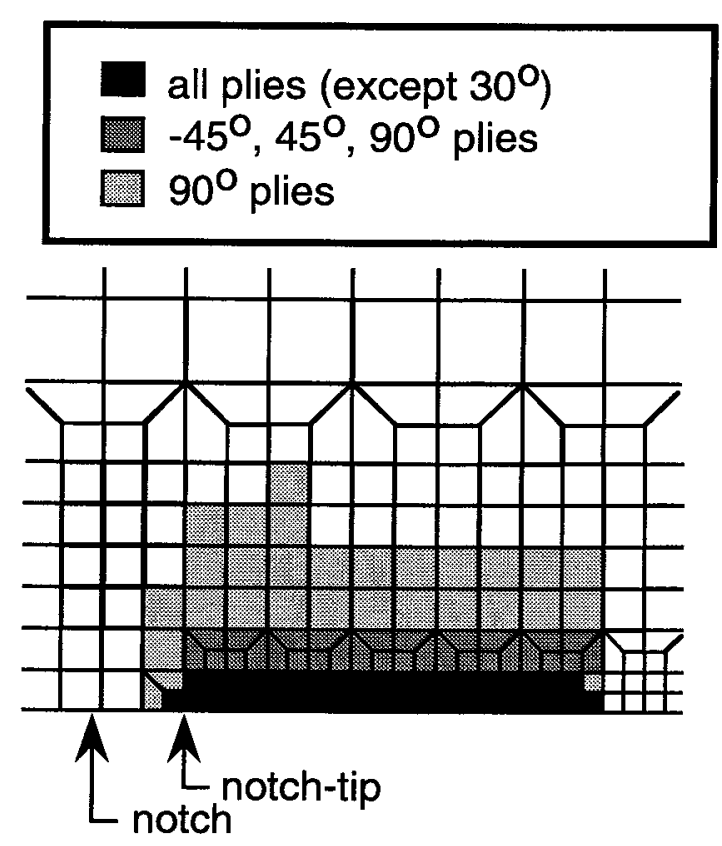

(b) Mode I Matrix Cracking $\left(\varepsilon_{22}>\varepsilon_{22}^{\mathrm{cr}}\right)$
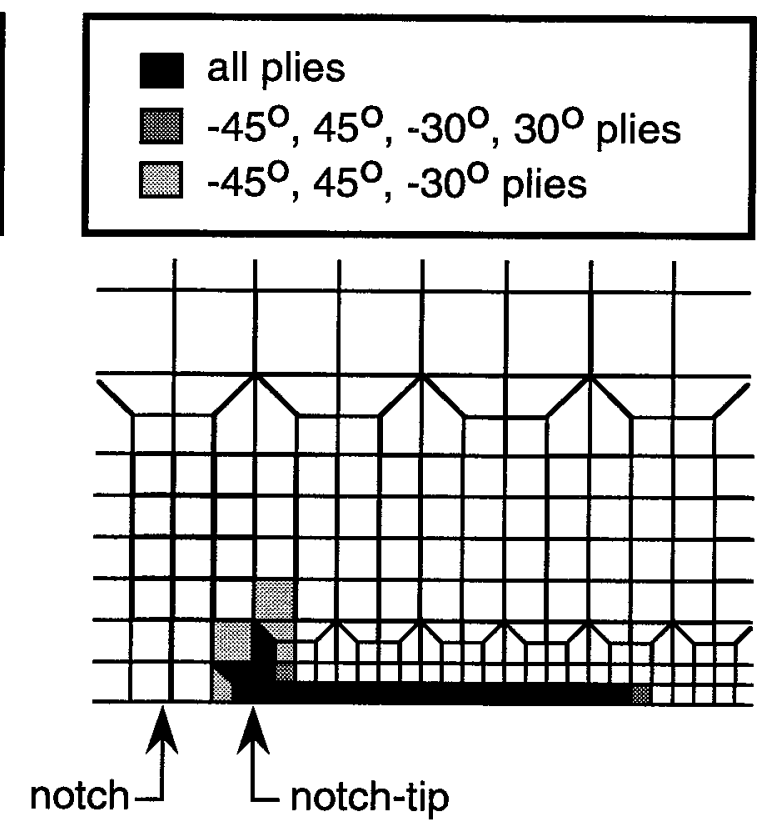

(c) Mode II Matrix Cracking

$$
\left(\gamma_{12}>\gamma_{12}^{0}\right)
$$

Figure 9. Damaged Elements Displayed for the AS4/938 Panel at $88 \%$ of the Ultimate Failure Load. Width $=91 \mathrm{~cm}, 2 \mathrm{a}_{\mathrm{o}}=22.9 \mathrm{~cm}$. 


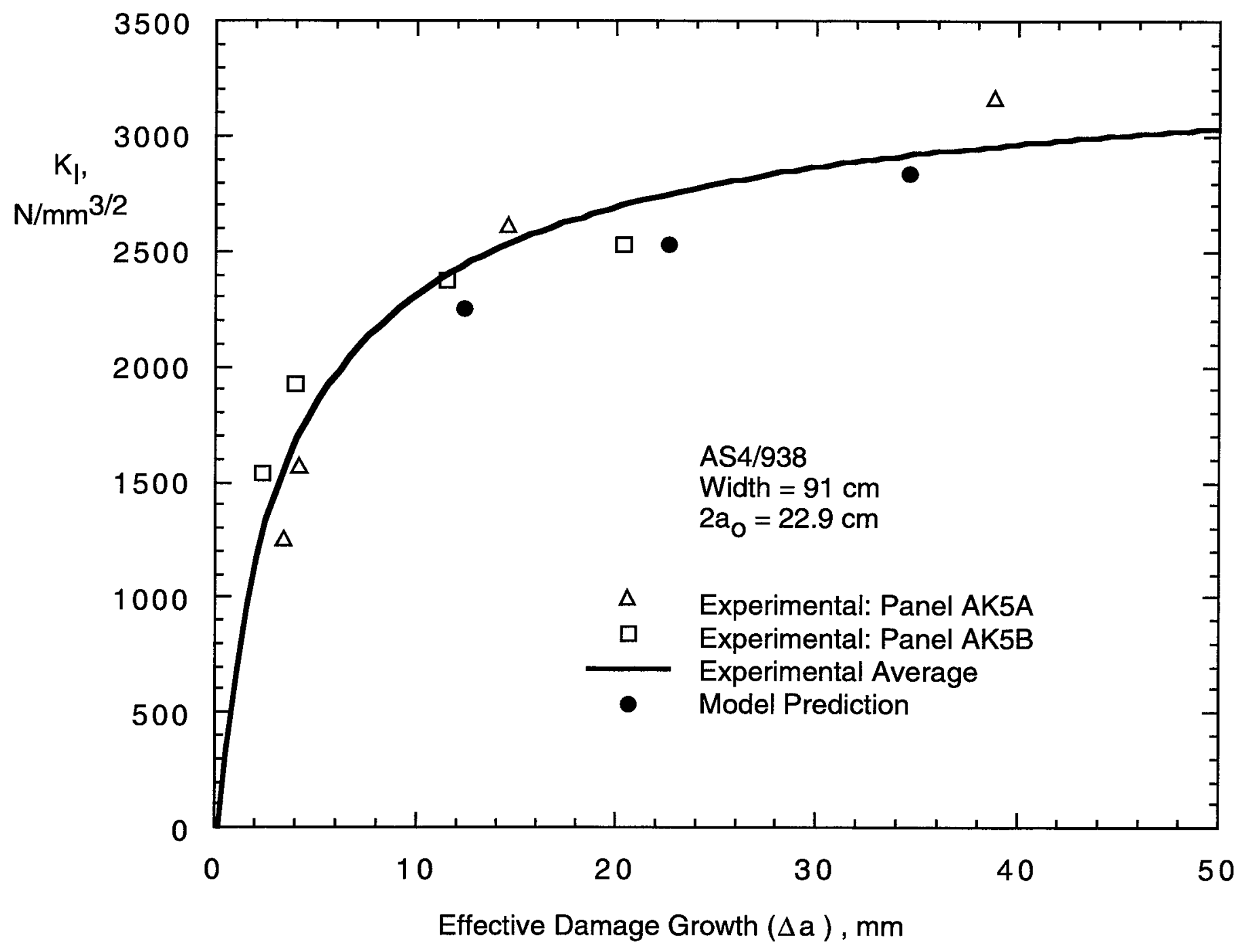

Figure 10. Experimental and Model Predicted Damage Growth Resistance. 


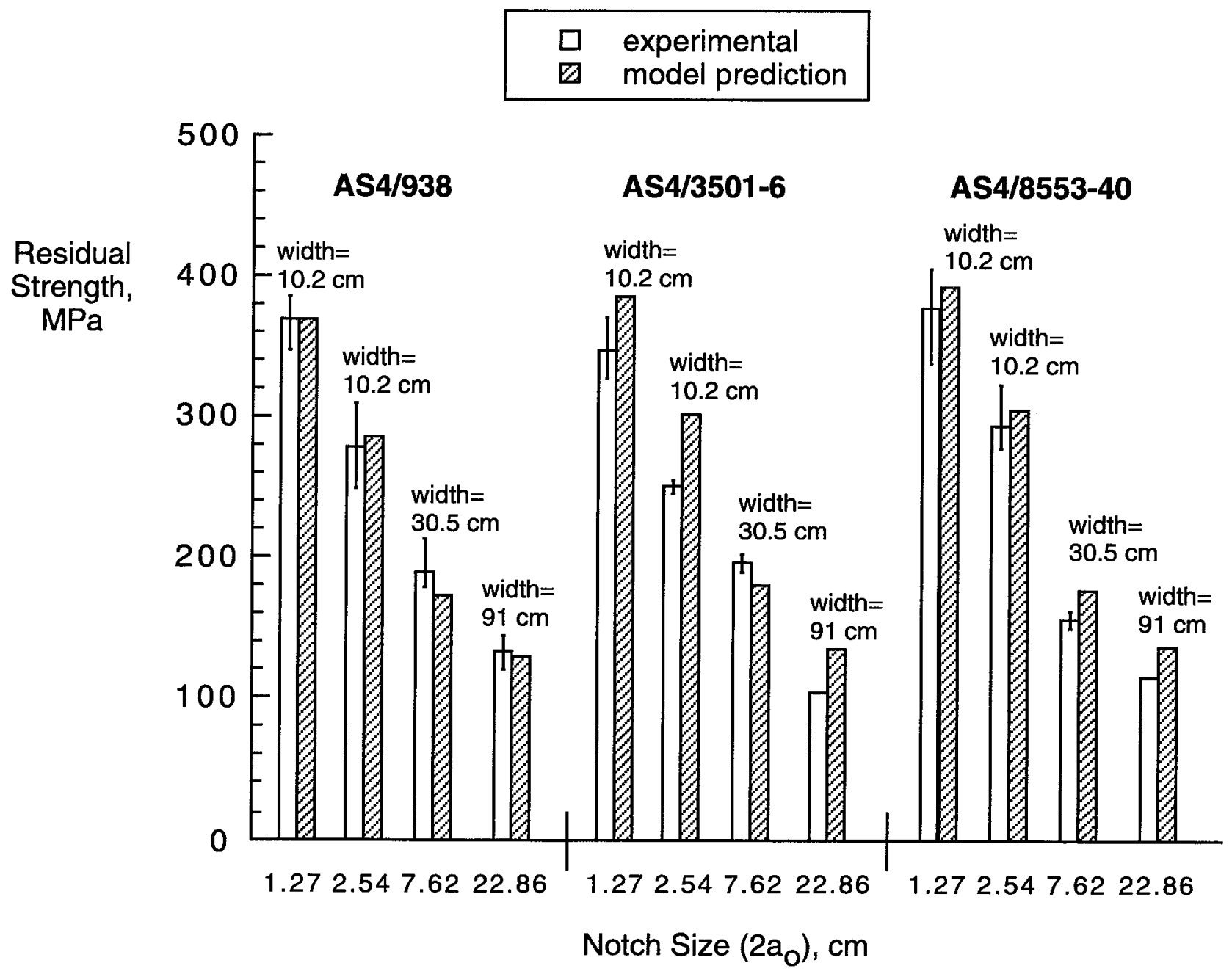

Figure 11. Residual Strength Predictions for the Center-Notch Tension Panels. 


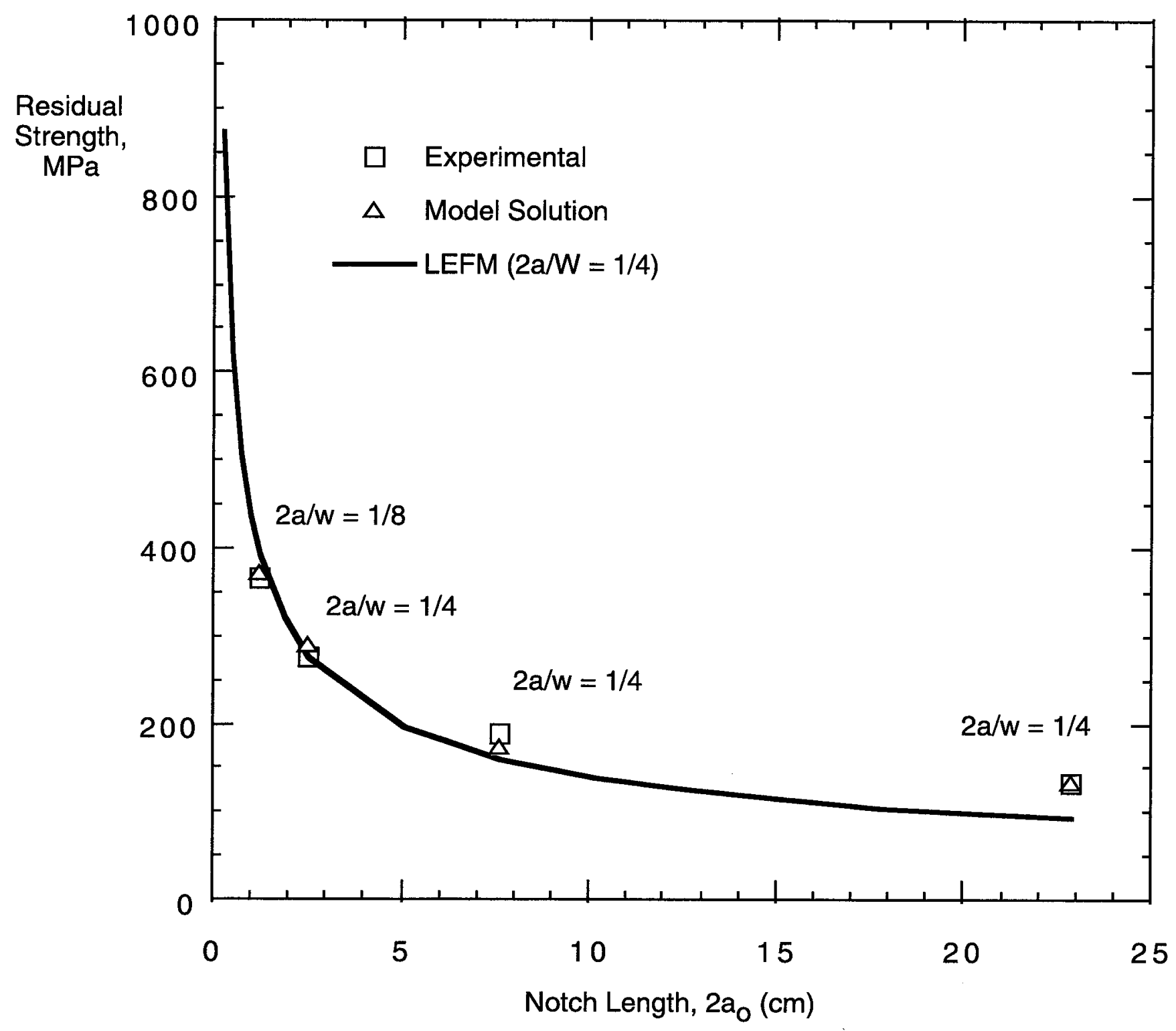

Figure 12. Comparison of LEFM and Model Prediction for the AS4/938 Center-Notch Tension Panels. 


\section{APPENDIX \\ Quantifying Damage Growth Resistance}

The notch-tip damage in a composite laminate is not a well defined and quantifiable crack like the notch-tip damage in metals, therefore, the terms crack growth and crack growth resistance may not be suitable for composites. The terms damage growth and damage growth resistance will be used when discussing composite laminates.

During the monotonic loading of the center-notch tension panels, the applied load and the COD at the center of the notch was recorded and used to produce load vs. COD plots, as was shown previously in Figure 3 for the AS4/938 specimen D1AK5A. The damage growth can be measured directly from these x-ray radiographs, or the load vs. COD plot can be used with a closed form solution to approximate the characteristic half-crack length, $a$. Using the change in $a$, the effective damage growth is determined as

$$
\Delta \mathrm{a}=\mathrm{a}-\mathrm{a}_{0}
$$

The closed form elasticity solution [27] for an isotropic material under plane stress is

$$
\mathrm{a}=\frac{\mathrm{COD}}{4 \varepsilon_{\mathrm{X}}}
$$

where $\varepsilon_{\mathrm{x}}$ is the uniaxial far-field strain, and the initial notch length is small compared to the panel width such that finite width effects are neglected. It can be shown that the closed form elasticity solution for determining the characteristic half-crack length for an orthotropic material under plane stress is

$$
\mathrm{a}=\frac{\mathrm{COD} \cdot \xi}{4 \varepsilon_{\mathrm{x}}}
$$

where $\zeta$ is a constant representing the effects of finite width and anisotropy. This is demonstrated in Figure A1 where the first loading up to discontinuity 'A' (in Figure 3) is plotted as COD vs. $\varepsilon_{\mathrm{x}}$. A schematic of the notch-tip damage is given to illustrate the configuration of the notch and damage. A linear regression analysis of the data for strains less than $1000 \mu \varepsilon$ provides an initial slope before damage initiation. From Figure A1 and equation (A3), one should observe that the initial slope is $4 \mathrm{a} / \zeta$. Since the initial slope is not 
affected by damage in this figure, the characteristic half crack length is equal to the initial half notch length, $a=a_{0}$. Therefore, for this specimen configuration and material, $\zeta$ is a constant equal to 0.83 . As damage increases, since $\zeta$ is a constant, the characteristic halfcrack length will be easy to determine.

The initial loading in Figure 3 was illustrated in Figure A1 as the COD vs. $\varepsilon_{\mathrm{X}}$ slope to demonstrate the calculation of the constant $\zeta$. Likewise, each consecutive loading is displayed as COD vs. $\varepsilon_{\mathrm{X}}$ in Figure $\mathrm{A} 2$ to demonstrate characteristic half-crack length calculations. The second, third, and fourth loadings are plotted up to their respective discontinuities. Again, a linear regression analysis was performed for strains less than $1000 \mu \varepsilon$ to provide an initial slope. The initial slope for the second loading is a result of the damage that occurred at the end of the first loading of Figure A1. As shown in Figure A2, this slope and the constant $\zeta$ are used to calculate the characteristic half-crack length that resulted from the damage at the end of the first loading. Equation (A1) is then used to calculate the effective damage growth. Likewise, $\Delta \mathrm{a}$ is determined for each of the slopes in Figure A2.

The effective damage growth, $\Delta \mathrm{a}$, and the critical stress responsible for the damage growth was used to plot $\mathrm{K}_{\mathrm{I}}$ vs. $\Delta \mathrm{a}$ where $\mathrm{K}_{\mathrm{I}}$ is the mode I stress intensity factor,

$$
K_{I}=\sigma_{c} \sqrt{\pi a \sec (\pi \mathrm{a} / \mathrm{w})} \text {. }
$$

This plot is a damage growth resistance curve (R-curve), as shown in Figure 10 of this paper. 


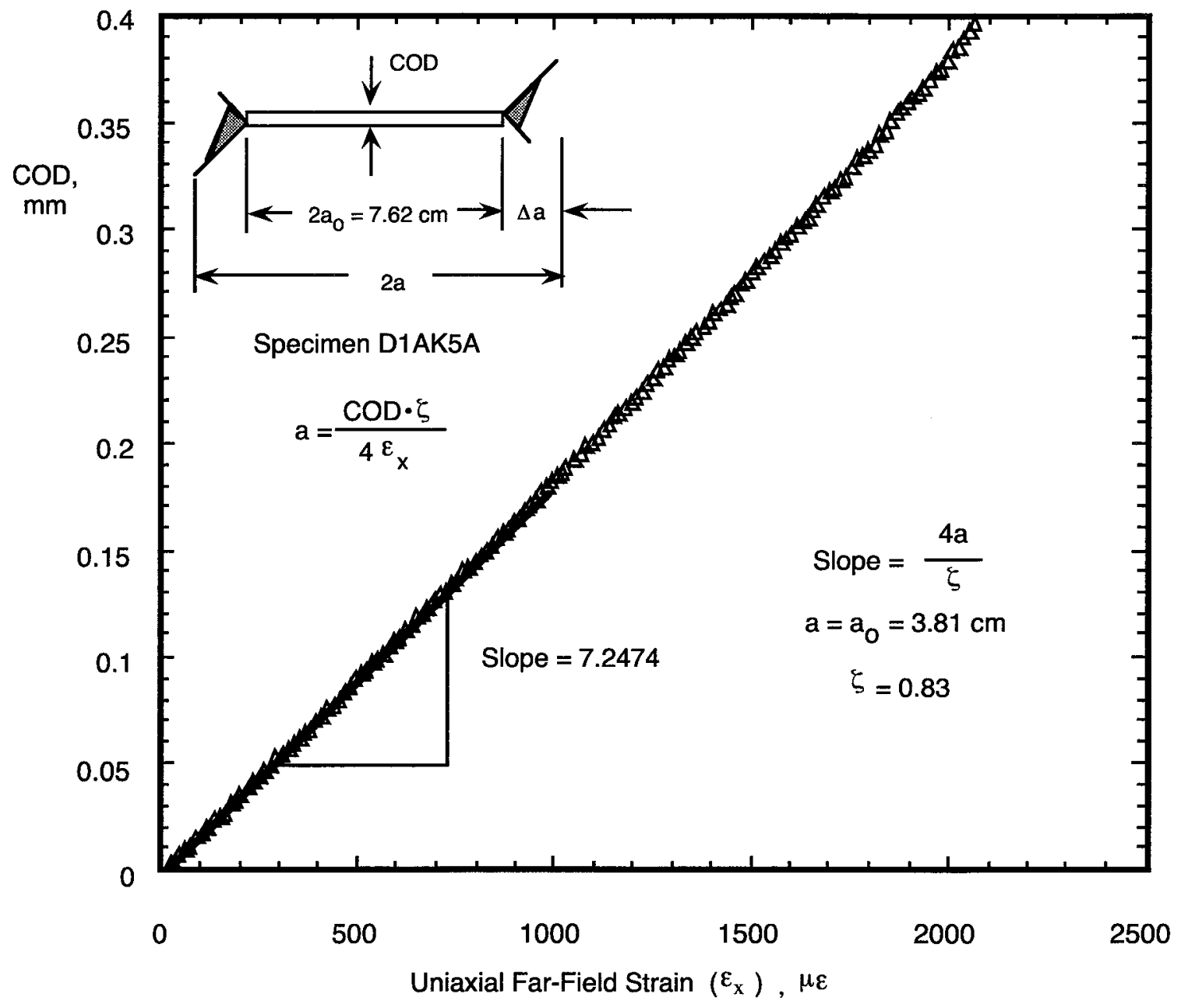

Figure A1. COD and Strain Data for Determining $\zeta$ for Panel D1AK5A. 


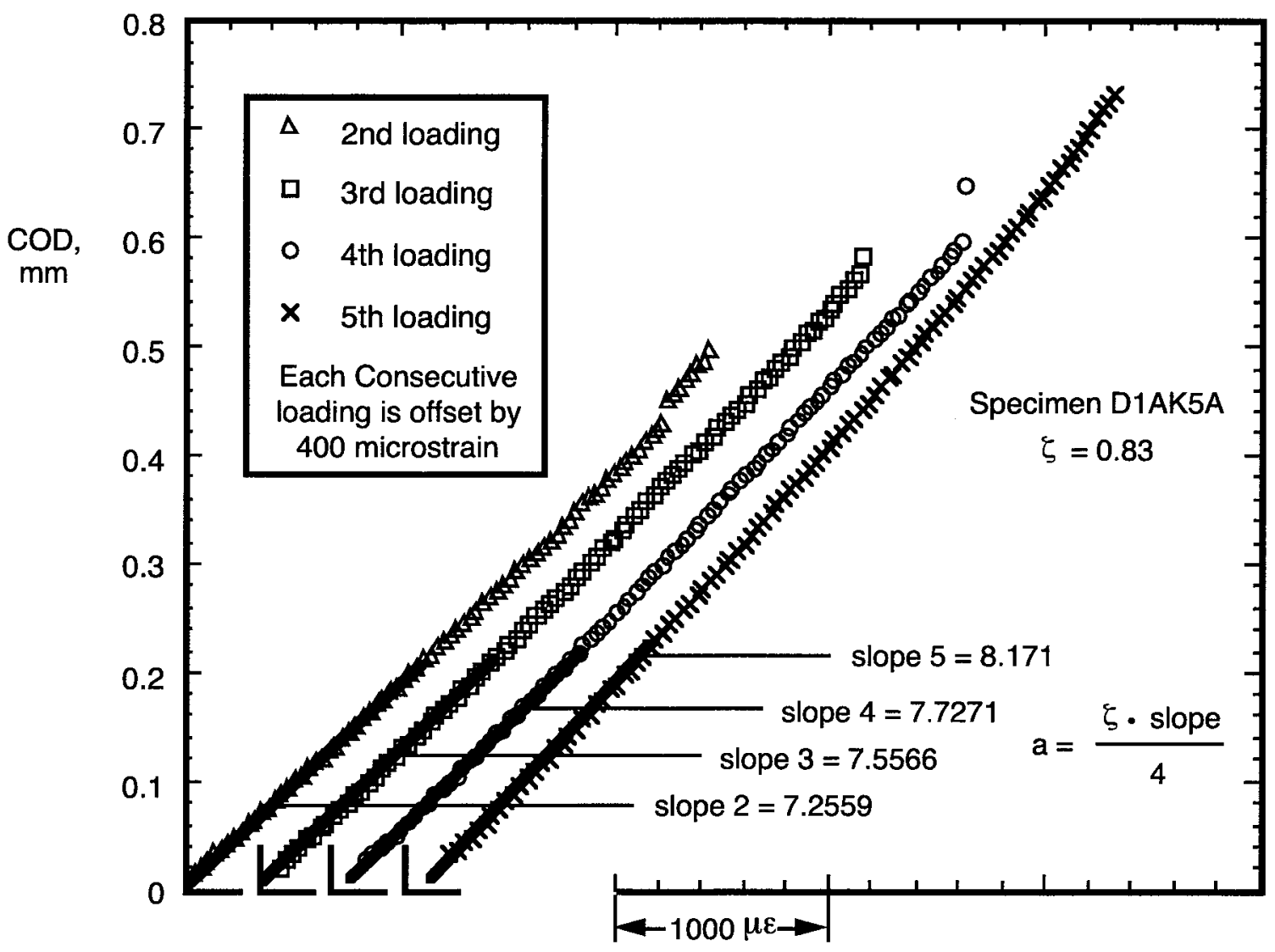

Uniaxial Far-Field Strain $\left(\varepsilon_{\mathrm{x}}\right), \mu \varepsilon$

Figure A2. COD and Slopes Used to Calculate $\Delta \mathrm{a}$. 


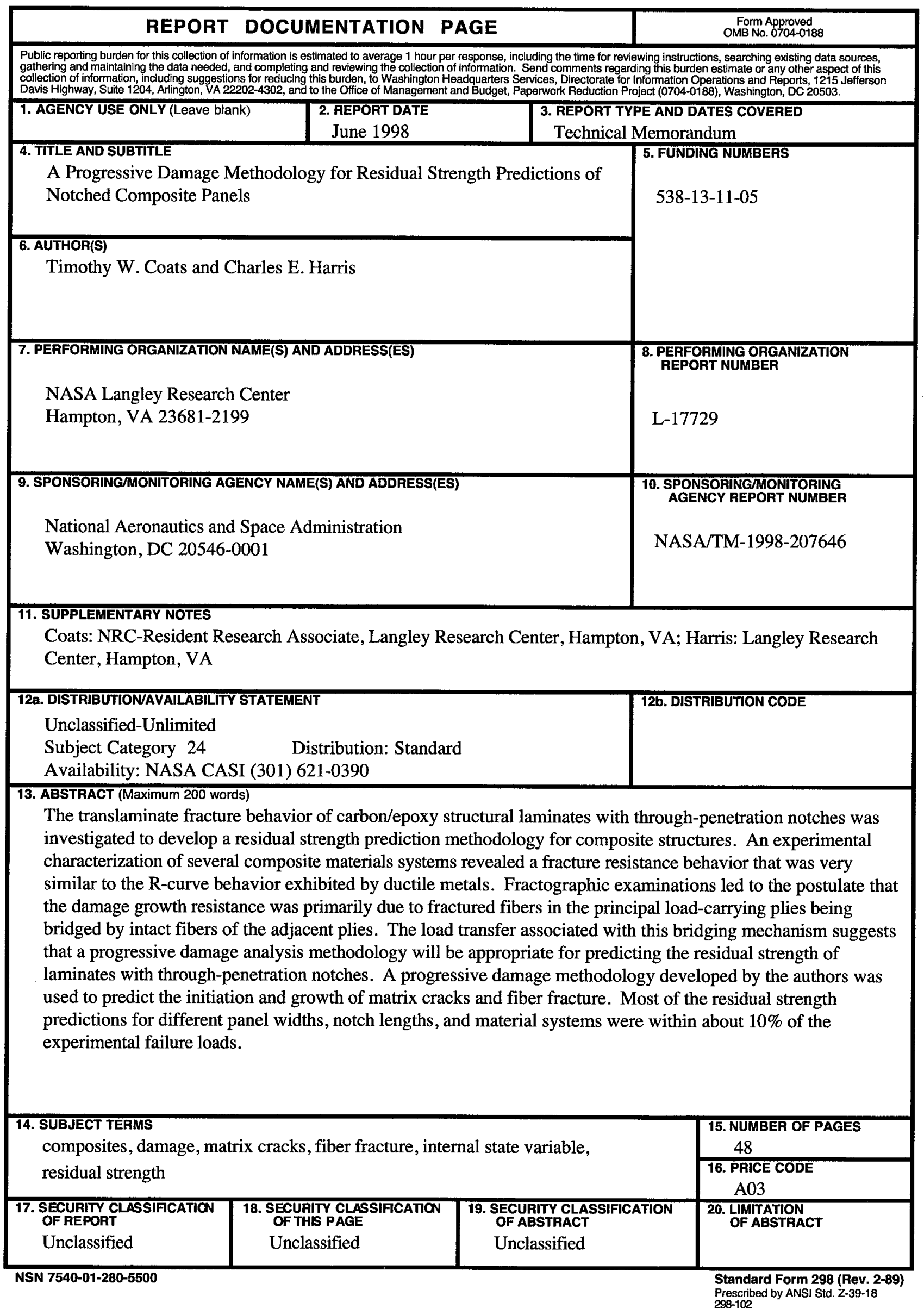

